\title{
UN APORTE A LA COMPRENSIÓN DE LAS ESTRATEGIAS EMERGENTES EN LAS ORGANIZACIONES A TRAVÉS DEL CONCEPTO DE IMPROVISACIÓN Y LA METÁFORA MUSICAL
}

\author{
MAURICIO SANABRIA* \& DIDDIER MORENO** \\ UNIVERSIDAD DEL ROSARIO
}

Recibido/ Received/ Recebido: 31/12/2016 - Aceptado/ Accepted / Aprovado: 28/02/2017

\begin{abstract}
Resumen
Este trabajo se inscribe en uno de los grandes campos de los estudios organizacionales: la estrategia. La perspectiva clásica en este campo promovió la idea de que proyectarse hacia el futuro implica diseñar un plan (una serie de acciones deliberadas). Avances posteriores mostraron que la estrategia podía ser comprendida de otras formas. Sin embargo, la evolución del campo privilegió en alguna medida la mirada clásica, estableciendo por ejemplo, múltiples modelos para 'formular' una estrategia, pero dejando en segundo lugar la manera en la que esta puede 'emerger'. El propósito de esta investigación es, entonces, aportar al actual nivel de comprensión respecto a las estrategias emergentes en las organizaciones. Para hacerlo, se consideró un concepto opuesto -aunque complementario- al de 'planeación' y, de hecho, muy cercano en su naturaleza a ese tipo de estrategias: la improvisación. Dado que este se ha nutrido de valiosos aportes del mundo de la música, se acudió al saber propio de este dominio, recurriendo al uso de 'la metáfora' como recurso teórico para entenderlo y alcanzar el objetivo propuesto. Los resultados muestran que: i) las estrategias deliberadas y las emergentes coexisten y se complementan, ii) la improvisación está siempre presente en el contexto organizacional, iii) existe una mayor intensidad de la improvisación en el 'cómo' de la estrategia que en el 'qué' y, en oposición a la idea convencional al respecto, iv) se requiere cierta preparación para poder improvisar de manera adecuada.

Palabras clave: Estrategias emergentes; Improvisación; Metáfora musical; Administración; Estudios organizacionales.
\end{abstract}

Doctor en Ciencias de Gestión de la Universidad de Caen (Francia). Diploma Universitario - Maestría de investigación de segundo año (Master II Recherche) en Ciencias de Gestión de la Universidad de Rouen (Francia). Magíster en Administración y Administrador de Empresas de la Universidad Nacional de Colombia. Profesor Titular y Profesor Distinguido de la Universidad del Rosario, Escuela de Administración, Bogotá, Colombia. Miembro del Grupo de Investigación en Dirección y Gerencia (GIDG), antes Grupo de Investigación en Perdurabilidad Empresarial (GIPE), en la Línea de Investigación en Estudios Organizacionales (LIEO). Editor de la Revista Universidad \& Empresa (U\&E). Miembro de la Red de Estudios Organizacionales Colombiana (REOC). Dirección postal: Escuela de Administración, Sede del Emprendimiento y la Innovación, Calle 200, entre la Autopista Norte y la Carrera 7, Módulo A (Bogotá). Teléfono: (571) 2970200 Ext. 3951. Correo electrónico: mauricio.sanabria@urosario.edu.co.

* Magíster en Dirección de la Universidad del Rosario, Escuela de Administración, Bogotá, Colombia, e Ingeniero Industrial de la Universidad Católica de Colombia. Correo electrónico: dmorenolopez@gmail.com. 


\title{
A CONTRIBUTION TO THE UNDERSTANDING OF EMERG- ING STRATEGIES IN ORGANIZATIONS THROUGH THE CON- CEPT OF IMPROVISATION AND THE MUSICAL METAPHOR
}

\begin{abstract}
This work is part of one of the great fields of organization studies: strategic management. The classical perspective in this field promoted the idea that projecting the organization to the future involves designing a plan (a series of deliberate actions). Further progress showed that the strategy could be understood in other ways. However, the evolution of the field privileged the classical view, to some extent, by establishing for example multiple models to 'formulate' a strategy, but leaving in a second place the way in which it can 'emerge'. The purpose of this research is then to contribute to the current level of understanding regarding the emerging strategies in organizations. To do so, it was considered an opposite - although complementary - concept to that of 'planning' and, in fact, very close in its nature to such kind of strategies: improvisation. Since this one has been nourished by valuable contributions of the music field, we used the knowledge of this domain, resorting to the use of 'the metaphor' as a theoretical resource to understand it and to reach the proposed objective. The results show that (i) deliberate and emerging strategies coexist and complement each other, (ii) improvisation is always present in the organizational context, (iii) there is a greater intensity of improvisation in the 'How' of strategy than in the 'What', and, as opposed to the conventional idea concerning this, (iv) some preparation is required in order to improvise properly. Keywords: Emerging strategies; Improvisation; Musical metaphor; Management; Organization studies.
\end{abstract}

\section{UMA CONTRIBUIÇÃO AO ENTENDIMENTO DAS ESTRATÉGIAS EMERGENTES NAS ORGANIZAÇÕES ATRAVÉS DO CONCEITO DE IMPROVISAÇÃO E A METÁFORA MUSICAL}

\section{Resumo}

Este trabalho inscreve-se em um dos grandes campos dos estudos organizacionais: a estratégia. A perspectiva clássica neste campo promoveu a ideia de que projetar para o futuro implica desenhar um plano (uma série de ações deliberadas). Avanços posteriores mostraram que a estratégia podia ser compreendida de outras formas. No entanto, a evolução do campo privilegiou de alguma forma o olhar clássico, estabelecendo por exemplo, múltiplos modelos para 'formular' uma estratégia, mas deixando em segundo lugar a maneira na que esta pode 'emergir'. O propósito desta pesquisa é, então, contribuir ao atual nivel de entendimento a respeito das estratégias emergentes nas organizações. Para fazê-lo, considerou-se um conceito oposto - ainda que complementar - ao de 'planejamento' e, de fato, muito próximo em sua natureza a esse tipo de estratégias: a improvisação. Dado que este se nutriu de valiosas contribuições do mundo da música, se foi ao saber próprio deste domínio, percorrendo o uso de 'a metáfora' como recurso teórico para entendê-lo e atingir o objetivo proposto. Os resultados mostram que: i) as estratégias deliberadas e as emergentes coexistem e complementam-se, ii) a improvisação está sempre presente no contexto organizacional, iii) existe uma maior intensidade de improvisação no 'como' da estratégia que no 'que' e, em oposição à ideia convencional a respeito, iv) se requer certa preparação para poder improvisar de maneira adequada. Palavras chave: Estratégias emergentes; Improvisação; Metáfora musical; Administração; Estudos organizacionais.

Sanabria, M. \& Moreno, D. (2018) Un aporte a la comprensión de las Estrategias Emergentes en las organizaciones a través del concepto de improvisación y la metáfora musical. En: Revista de la Facultad de Ciencias Económica: Investigación y Reflexión. rev.fac.cienc.econ, XXVI (1), DOI: https://doi.org/10.18359/rfce.2686

JEL: M19, B41, Y80. 


\section{Introducción}

El campo de la administración, de gran importancia para la dinámica empresarial y social, se ha desarrollado desde hace más de un siglo. Inspirándose en las teorías clásicas, específicamente en una parte de la obra de Fayol (1916/1917: 7-20), los diversos autores que lo han nutrido se han dedicado, en particular, a aplicar este campo de conocimientos a través de la consideración casi exclusiva del saber propio de las áreas funcionales. Trabajos recientes, sin embargo, han sugerido que para administrar se requiere no solo el saber funcional, sino algo más que esto (Vélez \& Garzón, 2005). Este aspecto adicional puede ser identificado como la dirección. Así, administración puede ser entendida como 'gerencia' más 'dirección' y los componentes básicos de esta última son: la estrategia, el liderazgo y la realidad empresarial (Vélez \& Garzón, 2005).

Este trabajo se sitúa entonces en uno de los grandes componentes de la dirección (Sanabria, 2014b): el campo de la estrategia, un cuerpo de saberes de gran desarrollo (Bowman, Singh, \& Thomas, 2002), fundamental para la administración. La visión clásica en este campo promovió la idea de que proyectar a las organizaciones hacia el futuro implica, básicamente, hacer un 'diseño' (Mintzberg, 1990a). Sin embargo, avances posteriores frente a esta perspectiva permitieron identificar que una estrategia puede ser comprendida de múltiples maneras (Mintzberg, 1987b), no necesariamente vinculadas con la idea de elaborar un plan rígido y estable.

Dentro de las formas alternativas para comprender este concepto se encuentra la consideración de que la estrategia se construye a través del tiempo, en la medida que avanza y evoluciona la organización, sin que para esto tenga que disponerse necesariamente de algún tipo de predeterminación. En otras palabras, que esta puede ser identificada también como un 'patrón', que emerge a partir de las acciones que realizan los actores en un cierto período (Mintzberg, 1987b).

En virtud de este avance, se considera hoy en el campo que no solo existen estrategias 'deliberadas' sino que también puede haber estrategias 'emer- gentes' (Mintzberg \& Waters, 1985). A pesar de que estas últimas han sido identificadas y que su existencia hoy es ampliamente aceptada, ellas no se han beneficiado de avances sustanciales desde su formulación inicial (Mintzberg, 1973, 1976, 1977, 1978, 1987b; Mintzberg, Raisinghani, \& Théorêt, 1976; Mintzberg \& Waters, 1985).

El propósito de este trabajo es aportar al incremento del actual nivel de comprensión respecto a las estrategias emergentes en las organizaciones. Para hacerlo, se aborda un concepto que, por su naturaleza, se vincula con procesos de este tipo: la improvisación. Dado que este ha sido ampliamente reconocido y desarrollado en otras áreas del saber cómo la música y el teatro, esta investigación, explorando una vía heurística (Abbott, 2004) ampliamente reconocida en el campo de la administración, recurre, como herramienta teórica y explicativa, al uso de metáforas (Morgan, 2006). Específicamente, se hace uso de la metáfora de la improvisación musical. La propuesta se articula entonces, por esta vía, al desarrollo del concepto, más bien reciente, de 'improvisación estratégica' (Bessudo, 2007; Patrick, 2008; Teoh \& Wickramasinghe, 2012).

En consonancia con lo anterior, la pregunta de investigación que dio vida a este trabajo fue:

¿Qué lugar puede ocupar la improvisación en la formación de estrategias emergentes?

El texto se estructura en cinco apartados básicos: el primero presenta la revisión de la literatura, el segundo la metodología, el tercero los resultados, el cuarto la discusión y el quinto las conclusiones.

\section{Revisión de la literatura}

\subsection{Fundamentos del campo de la estrategia}

El campo de la estrategia está bien definido (Hafsi, 2000; Hafsi \& Thomas, 2005; Sanabria, 2004) y sus aportes se destacan ampliamente en el contexto de los estudios organizacionales (Sanabria, Saavedra Mayorga, \& Smida, 2014). Su evolución, en particular, a lo largo de las últimas seis décadas, ha estado marcada por el desarrollo de múltiples pers- 
pectivas teóricas y prácticas (Sanabria \& Smida, 2015). En efecto, a lo largo de este proceso múltiples representaciones acerca del concepto de estrategia han surgido (Mintzberg, 1987b), así como determinadas escuelas, claramente establecidas, las cuales le han permitido al campo adquirir una forma reconocible y bien consolidada (Mintzberg, Ahlstrand, \& Lampel, 1998).

Los antecedentes del uso de la estrategia, en el contexto empresarial moderno, se remontan principalmente a la década de 1820 , en particular a las consecuencias, en este ámbito, de invenciones como la máquina de vapor y la construcción de grandes obras como los ferrocarriles. Estas permitirian, entre otras cosas, integrar amplios territorios como el estadounidense. Sin embargo, el enfoque directivo, desde aquel entonces y durante más de un siglo, se centró en crear y usar tecnologías y métodos que, profundizando las consecuencias de la Revolución Industrial, permitieran producir de manera eficiente y lograr la mayor participación posible en el mercado (Ansoff \& McDonnell, 1990). Solo después de la década de 1940, la estrategia comienza a adquirir una clara importancia en el contexto organizacional y, en particular, a tomar forma como campo de conocimientos. Esto superando el tradicional enfoque que por siglos dominó la proyección organizacional hacia el futuro, es decir: los presupuestos y las consideraciones económicas y financieras. Así, desde esa década y, en particular, a partir de los años sesenta y setenta, comienza a tomar forma el campo del Strategic Management en cuanto tal (Ansoff, Declerck, \& Hayes, 1976; Schendel \& Hofer, 1979).

La definición inicial del concepto de 'estrategia', al interior del naciente campo de conocimientos, emerge de la mano de la mirada clásica en el mismo, es decir, en el transcurso de los sesenta y setenta (Sanabria, 2004). Esta lo establece como "un plan -algún tipo de consciente y premeditado curso de acción, un lineamiento (o conjunto de lineamientos) para lidiar con una situación" (Mintzberg, 1987b; 11). Desde esta concepción, la estrategia corresponde a un proceso en el que, primero, se define con claridad lo que se pretende lograr y cómo hacerlo y, luego, se implementa, controlando que lo planeado se realice tal y como estaba previsto. Lo anterior, entonces, supone que esta tiene que ver esencialmente con un 'diseño' (Mintzberg, 1990a).

A esta visión, considerada como clásica, un grupo de autores opuso la idea de que la estrategia no solo puede ser vista como un 'plan', sino que también puede llegar a ser pensada, entre otras alternativas (Mintzberg, 1987b), como un 'patrón' generado al interior de un conjunto de acciones posibles. En otras palabras, que esta puede corresponder a un comportamiento que, al ser de algún modo coherente a través del tiempo, es identificable dentro del conjunto de actividades que desarrolla una organización (Mintzberg \& Waters, 1985).

Esta contracorriente denunció la existencia de una especie de obsesión por considerar al directivo como un 'arquitecto' de la estrategia, algo que, entre otras cosas, generó un afamado debate entre Mintzberg (1990a) y Ansoff (1991). El primero cuestionó la escuela del 'diseño', en particular, el protagonismo que ella otorga a los directivos de alto nivel en la organización y la idea de que la formación de la estrategia corresponde a un proceso consciente, controlado, pensado y deliberado, el cual debe ser desarrollado por completo antes de llegar a su etapa de implementación. El segundo respondió a las acusaciones, denunciando deficiencias metodológicas del primero y acusándolo de hacer afirmaciones que no correspondían ni con los hechos ni con la propia evolución del campo.

El debate continuó con una respuesta de Mintzberg (1991), indicando que más que a Ansoff, él se refería a autores como Andrews (1971/1980; Learned, Christensen, Andrews, \& Guth, 1965/1969), pues a este lo ubicaba como un protagonista de la escuela del 'diseño', mientras a aquel como un representante destacado no de esta, sino de la perspectiva de la 'planeación' (Mintzberg, 1990c). Aunque en el texto se termina sugiriendo una mirada conciliadora $y$ de coexistencia entre el aprendizaje incremental y la planeación deliberada en las organizaciones (Mintzberg, 1991), la cual autores como Goold (1992) buscaron aclarar, Mintzberg reafirmó sus consideraciones básicas acerca de la mirada clásica, las cuales se dedicó luego a desarrollar de manera 
más amplia, profunda y fundamentada (Mintzberg, 1994; Mintzberg et al., 1998).

A partir de lo anterior, surgen en el campo de la estrategia dos líneas de trabajo, al interior de otras posibles (Whittington, 1993), en cuyo desarrollo participarán varios prestigiosos autores. La primera, la mirada clásica, considera a la estrategia como un diseño, como algo que es establecido a priori o, en otras palabras, como un plan deliberado. La segunda, por su parte, aunque sin desconocer la existencia de la primera (Mintzberg, 1978), hace énfasis en que la estrategia no necesariamente corresponde a un diseño o a un plan, sino que se va definiendo en el día a día de la organización, durante su ejecución y que, en consecuencia, más que a un proceso de 'formulación', corresponde a uno de 'formación'. Con esto se establece el espacio para hablar de 'estrategias deliberadas' y 'estrategias emergentes', asî como un conjunto de posibilidades adicionales entre una y otra (Mintzberg \& Waters, 1985) o incluso, como más recientemente se ha propuesto, el eventual establecimiento de un ciclo entre ambas (Montoya, 2010: 139-142).

\subsection{Las estrategias deliberadas y emergentes}

En la tradición del campo, las estrategias deliberadas son entendidas usualmente como un diseño establecido a priori por un individuo o un grupo de estos - ubicado(s) por lo general en el más alto nivel jerárquico de la compañía-, a través de un proceso de planeación bien determinado (Ansoff \& Hayes, 1976; Chaffee, 1985). Más estrictamente, estas pueden ser comprendidas como el camino directo entre una estrategia pretendida y una lograda (Mintzberg \& Waters, 1985: 258), es decir, como aquellas que son "realizadas [justo] como se pretendió" (Mintzberg \& Waters, 1985: 257). De acuerdo con la literatura más usual, el diseño a través del cual se plantean este tipo de estrategias, es luego ejecutado y controlado. Esto último, de manera específica, para verificar su realización efectiva. La idea entonces, en este contexto, es que la estrategia se 'formula' y que la actividad que da fundamento a este tipo de procesos es la 'planeación'.
Las estrategias emergentes, por su parte, constituyen "patrones en corrientes de acciones" (Mintzberg \& Waters, 1985: 257). Más estrictamente, pueden ser definidas como "patrones o consistencias realizadas a pesar, o en ausencia de, intenciones" (Mintzberg \& Waters, 1985: 257). En ellas intervienen mecanismos como el aprendizaje y la actuación por medio del ensayo y el error. Dada su definición, su principal fundamento se encuentra no en la planeación, como en el caso de las estrategias deliberadas, sino en la 'implementación', la ejecución o, en otras palabras, la realización de las acciones organizacionales. La estrategia, en este contexto, no se formula, sino que "puede formarse gradualmente" (Mintzberg, 1978: 935).

Ahora bien, de acuerdo con Mintzberg \& Waters (1985: 258-259), es extraño o muy poco probable que, en la práctica cotidiana, en el medio organizacional, existan estrategias deliberadas o emergentes puras. Lo que es posible encontrar, según estos autores, es la existencia de determinadas estrategias con tendencias más o menos marcadas hacia las unas o las otras.

A pesar del planteamiento de que las estrategias pueden ser deliberadas o emergentes y de que entre los dos extremos teóricos que estas constituyen es posible encontrar estrategias de otros tipos (ver tabla 1), en la evolución del campo se estableció, a la manera de una corriente principal $-\mathrm{O}$ mainstream - un determinado privilegio por desarrollar más el conocimiento vinculado con las primeras que con las segundas (Hitt, Ireland, \& Hoskisson, 2013; Wheelen, Hunger, Hoffman, \& Bamford, 2014). Esto, probablemente, debido al hecho que las estrategias deliberadas se han estudiado y desarrollado, como se ha indicado, desde el origen mismo del discurso estratégico (Hofer \& Schendel, 1978). Como resultado, el nivel de comprensión que se tiene en la actualidad acerca de las mismas es amplio y profundo (Andrews, 1971/1980; Ansoff, 1965; Learned et al., 1965/1969; Schendel \& Hofer, 1979). 
Tabla 1. Diversos tipos de estrategias, desde las deliberadas hasta las emergentes

\begin{tabular}{|c|c|c|}
\hline $\begin{array}{l}\text { Tuning } \\
\text { (Sintonización o } \\
\text { afinación) de factores } \\
\text { distintivos }\end{array}$ & $\begin{array}{c}\text { Tipo de } \\
\text { estrategia }\end{array}$ & Características básicas \\
\hline \multirow{10}{*}{$\begin{array}{c}\text { - Priman las intenciones } \\
\text { del líder. } \\
\text { - Control } \\
\text { - Centralidad } \\
\text { - Inflexibilidad } \\
\text { - Entorno benigno. } \\
\text { - Certidumbre }\end{array}$} & $\begin{array}{l}\text { Deliberada } \\
\text { (pura). }\end{array}$ & $\begin{array}{l}\text { Realizada tal cual como fue pretendida: el camino directo entre una estrategia propuesta y una realizada. } \\
\text { Para que se dé: } \\
\text { - Debe haber intenciones precisas en la organización -en un nivel de detalle bien concreto- - presen- } \\
\text { tes antes de que se tome cualquier acción. } \\
\text { - Las intenciones deben ser comunes para todos los participantes de la organización. } \\
\text { - Las acciones deben haber sido realizadas tal cual, como fue la intención original. } \\
\text { - Ninguna fuerza externa (mercado, tecnológica, política, etc.) interfiere o está por fuera del completo } \\
\text { control de la organización. }\end{array}$ \\
\hline & Planeada & $\begin{array}{l}\text { Las estrategias se originan en planes formales: aquí y solo aquí la diferenciación entre formulación e } \\
\text { implementación se sostiene. Existen intenciones precisas que son formuladas y articuladas por el lide- } \\
\text { razgo central, respaldadas por controles formales para asegurar una implementación "sin sorpresas". } \\
\text { Consideran un entorno benigno, controlable y (al menos) predecible (algunas organizaciones pueden } \\
\text { imponerse en el entorno o predecirlo y ajustarse). Las estrategias son principalmente deliberadas. }\end{array}$ \\
\hline & Empresarial & $\begin{array}{l}\text { Las estrategias se originan en una visión central: las intenciones existen como una visión personal de } \\
\text { un líder, no necesariamente articulada a los otros. Son adaptables a nuevas oportunidades. La orga- } \\
\text { nización está bajo el control personal del líder y se encuentra localizada en un nicho con un ambiente } \\
\text { protegido y cooperativo. Las estrategias son relativamente deliberadas, pero pueden emerger. }\end{array}$ \\
\hline & Ideológica & $\begin{array}{l}\text { Las estrategias se originan en creencias compartidas: las intenciones existen como una visión colec- } \\
\text { tiva de todos los actores de forma inspiradora, relativamente inmutable y controlada normativamente } \\
\text { a través del adoctrinamiento y la socialización. La organización es frecuentemente proactiva frente al } \\
\text { entorno. Las estrategias son más bien deliberadas. }\end{array}$ \\
\hline & Sombrilla & $\begin{array}{l}\text { Las estrategias se originan en restricciones: el liderazgo, en control parcial de las acciones organi- } \\
\text { zacionales, define los límites organizacionales, los lineamientos generales de comportamiento y los } \\
\text { objetivos al interior de los cuales los otros actores responden a las propias fuerzas o al complejo y tal } \\
\text { vez impredecible entorno. Este debe convencer a los otros, pues no tiene el control sobre la realización } \\
\text { de la estrategia. Él detiene, ignora o ajusta el comportamiento de los otros cuando se "salen de curso". } \\
\text { Las estrategias son parcialmente deliberadas, parcialmente emergentes y deliberadamente emergentes. }\end{array}$ \\
\hline & De proceso & $\begin{array}{l}\text { Las estrategias se originan en los procesos: el liderazgo controla aspectos del 'proceso' de la estrategia } \\
\text { (contratación, estructura, etc.), dejando asuntos relativos al 'contenido' a otros actores. Las organizacio- } \\
\text { nes en divisiones o conglomerados usan esta estrategia (la casa matriz o el “cuartel general” establece la } \\
\text { estructura, el control y los directivos; luego, en este contexto, dan libertad y autonomía). Las estrategias } \\
\text { son parcialmente deliberadas, parcialmente emergentes (y, nuevamente, deliberadamente emergentes). }\end{array}$ \\
\hline & Inconexa & $\begin{array}{l}\text { Las estrategias se originan en enclaves: actor(es) débilmente vinculado(s) al resto de la organización } \\
\text { produce(n) patrones en las propias acciones, en ausencia de o, en directa contradicción con, las in- } \\
\text { tenciones centrales y comunes. Universidades, hospitales y otros pueden funcionar así. Cada actor } \\
\text { puede perseguir sus propias estrategias (cuidado del paciente, método de enseñanza o investigación). } \\
\text { Las estrategias son organizacionalmente emergentes, ya sean deliberadas o no para el(los) actor(es). }\end{array}$ \\
\hline & De consenso. & $\begin{array}{l}\text { Las estrategias se originan en el consenso: a través del ajuste mutuo, los actores convergen en patro- } \\
\text { nes que llegan a ser penetrantes, sin la necesidad de un control central y de intenciones comunes. Las } \\
\text { estrategias son más bien emergentes, surgen del mutuo ajuste entre el comportamiento de los actores } \\
\text { y no de intenciones o de un manejo central. }\end{array}$ \\
\hline & Impuesta & $\begin{array}{l}\text { Las estrategias se originan en el ambiente: el entorno dicta patrones en las acciones, ya sea a través } \\
\text { de la imposición directa } 0 \text { a través de vaciar implícita y previamente } 0 \text { limitar la elección organizacional. } \\
\text { Las estrategias son principalmente emergentes, aunque pueden ser internalizadas por la organización } \\
\text { y tornarse así en deliberadas. }\end{array}$ \\
\hline & $\begin{array}{l}\text { Emergente } \\
\text { (pura). }\end{array}$ & $\begin{array}{l}\text { Un patrón de comportamiento realizado en ausencia de intenciones: el logro de una estrategia llevada } \\
\text { a cabo con base en un patrón identificable en una corriente de acciones. Esto en ausencia de una } \\
\text { estrategia propuesta. Para que se dé: } \\
\text { Debe haber orden y consistencia en la acción a lo largo del tiempo, en ausencia de intención acerca de } \\
\text { la misma. Si no hay consistencia no habría estrategia o sería "no realizada". } \\
\text { Existen estrategias que se acercan como, por ejemplo, cuando un ambiente impone directamente un } \\
\text { patrón de acciones a una organización. }\end{array}$ \\
\hline
\end{tabular}

Fuente: elaborada a partir de Mintzberg \& Waters (1985: 270), aunque usando información de toda la obra (pp. 258-259 y otras). 
Aunque se ha producido también una importante cantidad de trabajos alrededor de la idea de la estrategia como un fenómeno emergente, la mayoría de estos se ha limitado, en lo fundamental, a hacer uso del concepto establecido (Andersen \& Nielsen, 2009; Bozkurt \& Kalkan, 2013; Kipping \& Cailluet, 2010; Lowe \& Jones, 2004). De este modo, salvo por ciertos trabajos destacados (Hernández, Montoya, \& Montoya, 2015; Montoya, 2010; Montoya \& Montoya, 2010, 2013; Roge, 1996), algunos de estos dedicados incluso al concepto de 'emergencia' (Montoya \& Montoya, 2015), las investigaciones y avances no se han concentrado, en lo fundamental, a tratar de incrementar el nivel de comprensión que se tiene en la actualidad respecto a este tipo de estrategias.

Un recurso útil para tratar de contribuir a llenar este vacío que, de hecho, ha sido utilizado antes también, por ejemplo, por algunos de los estudios citados en el párrafo anterior y por otros investigadores más en diversos campos del conocimiento, es hacer uso de metáforas. Esta herramienta teórica es usada con el fin de procurar el desarrollo de avances en un determinado dominio, a partir de conceptos, ideas, imágenes o planteamientos que se encuentran más naturalmente ubicados y desarrollados en otros. Se considera viable y plausible, en efecto, hacer uso de este instrumento, para tratar de aportar al desarrollo del actual nivel de comprensión acerca de las estrategias emergentes. La fundamentación de este dispositivo se presenta a continuación.

\subsection{Las metáforas en el campo de los estudios organizacionales}

Considerada ampliamente, como indican Sommer y Weiss (1995):

Ya sea poética o coloquial, simple o compleja, una metáfora compara dos objetos o ideas diferentes e ilumina las similitudes entre ellos. Esto se logra en una palabra o frase que podría de otro modo ser expresada únicamente en muchas palabras, si acaso (...). Dado que la palabra o frase que se usa para establecer la comparación evoca una imagen mental, se podría decir que la metáfora encarna la frase "una imagen vale más que mil palabras”. (p. vii)

Una metáfora se crea "cuando un término (a veces referido como una 'fuente') es transferido desde un sistema o nivel de significado a otro (el 'objetivo'), iluminando así aspectos centrales del último" (Alvesson \& Spicer, 2011: 34). Significa, entonces, una transferencia de "un concepto/objeto/atributo a otro, comparando algo en un dominio con un elemento en otro dominio" (Wormeli, 2009: 6). Las metáforas constituyen una "fuerza creativa" (Heracleous \& Jacobs, 2011: xvii) que, de hecho, se encuentra presente "en todas partes en el lenguaje que utilizamos” (Goatly, 1997: 2).

Las metáforas constituyen un recurso valioso para el desarrollo de la ciencia en las diferentes áreas del saber (Czarniawska, 2011; Leatherdale, 1974; Mihram \& Mihram, 1974). En el contexto de los estudios organizacionales, estas han sido también importantes para la comprensión del campo y sus actividades de 1) investigación (Burrell, 1996; Cornelissen, Oswick, Christensen, \& Phillips, 2008; Inns, 2002; Morgan, 2006; Örtenblad, Putnam, \& Trehan, 2013), 2) enseñanza (Beatty, 2004; Taber, 2007), 3) producción de teoría para dar sustento a su evolución (Manning, 1979; Morgan, 1980), su labor práctica (Czarniawska, 2004) y 4) interrelación y mutuo aporte con otros dominios del conocimiento (Montoya, Montoya, \& Castellanos, 2010; Montoya, Castellanos, \& Montoya, 2004). Así, por ejemplo, haciendo uso de esta herramienta teórica, se ha considerado ver a la organización como una máquina, un organismo, un cerebro, una cultura, un sistema político, una prisión psíquica, un flujo y transformación y un sistema de dominación (Morgan, 2006).

Las metáforas han permitido también poner en relación campos como el de la música y el análisis organizacional (Mantere, Sillince, \& Hämäläinen, 2007), vinculando elementos que, aunque disímiles en su origen, presentan determinadas semejanzas que resultan ser útiles para comprender ciertos fenómenos organizacionales. Así, por ejemplo, entre estos dos contextos es posible considerar entre otros aspectos, en términos metafóricos, cómo 'la 
forma de las piezas musicales' se relaciona con la estructura organizativa, 'el volumen' con el control y manejo eficiente de recursos, 'la armonía' con la solución de problemas internos, 'el ritmo' con los tiempos y plazos que deben ser cumplidos para la entrega de algún proyecto y, por último, 'la textura' con el tipo de personalidad, posiciones o grupos de interés inherentes a los objetivos de la empresa.

Así, por su riqueza, parece útil seguir haciendo uso de este recurso, de alto valor para la actividad de comprensión en el contexto de la investigación organizacional, en campos como el de la estrategia. En realidad, desde una perspectiva heurística (Abbott, 2004), este puede permitir continuar vinculando de manera efectiva dominios como el de la música y el de los estudios organizacionales y, en particular, en el contexto de este estudio, por ejemplo, poner también en relación conceptos como el de improvisación y el de estrategia. Esto, de hecho, puede contribuir igualmente al desarrollo de la noción de 'improvisación estratégica' (Rasche, 2008: 234), la cual está en construcción tanto por parte de teóricos (Patrick, 2008) como de practicantes (Bessudo, 2007) del mundo de la administración. La improvisación, de hecho, es considerada en el trabajo que aquí se plantea - esto a la manera de una proposición de investigación- como un aspecto vinculado, de algún modo, a las estrategias emergentes.

\subsection{La improvisación musical como metáfora útil para avanzar hacia una más amplia com- prensión de las estrategias emergentes}

El uso de la música, como metáfora útil para el campo de los estudios organizacionales, no es algo nuevo (Barrett, 1998; Bastien \& Hostager, 1988; Meyer, Frost, \& Weick, 1998; Oakes, 2009). Este recurso ha permitido aportar al entendimiento de múltiples procesos organizacionales, en especial, partiendo del concepto de improvisación (Hatch, 1999; Meyer et al., 1998; Weick, 1998). La labor realizada ha establecido puentes que han logrado conectar dos campos aparentemente disímiles y distantes y ha contribuido a desarrollar una más amplia comprensión de la realidad organizacional ampliamente considerada (Soubeyran, 2014; Weick, 1998).
En la actualidad, como resultado de lo anterior, el concepto de improvisación, por ejemplo, ya no es ajeno al campo de los estudios organizacionales y, de hecho, está ganando cada vez más importancia en los múltiples dominios que le dan forma (Arshad, 2011; Cunha, Clegg, \& Kamoche, 2012; Cunha \& Cunha, 2006; Duxbury, 2014; Kamoche, Cunha, \& Cunha, 2003; Kamoche, Cunha, \& Cunha, 2002; McDaniel, 2007; Montuori, 2012; Vendelø, 2009).

Dentro de las diversas metáforas que han permitido vincular el concepto de improvisación a múltiples problemáticas propias del campo de los estudios organizacionales, el 'jazz' ha ocupado un lugar privilegiado (Barrett, 1998; Bastien \& Hostager, 1988; Hatch, 1999; Kamoche et al., 2003). Este género musical encuentra su origen en Estados Unidos, gracias a una serie de condiciones sociales, políticas y culturales propias de los inicios del siglo XIX. Estas, de hecho, hicieron posible su surgimiento. El jazz se nutre de la espontaneidad, la creatividad y la expresión. Por esta razón, facilita la conexión de las habilidades individuales del músico, a través de la innovación, con el trabajo colectivo de quienes integran su banda (Bastien \& Hostager, 1988).

Es probable que las raíces rítmicas del jazz provengan de los sonidos africanos que acompañaron por más de 400 años a los esclavos que habitaban las regiones cercanas a Nueva Orleans. Sin embargo, parece que este surge, en mayor medida, por el encuentro de los negros y los blancos, ya que su concepto melódico y armónico es más cercano a la música europea que a la africana.

Entender la evolución de este género musical implica observar una división, a lo largo de varios decenios, dentro de los cuales la improvisación va haciendo su aparición, para convertirse gradualmente en un componente central de este género (Read, 2014) (ver tabla 2). Sin embargo, hay que reconocer la influencia que tiene el 'blues' en la improvisación jazzística, ya que este se dio primero y, de acuerdo con autores como Berendt (1994), es de algún modo la fuente de dicha práctica en el contexto del jazz. Esto en el marco de una tensión creativa generada entre la libertad del solista y sus deberes para con sus compañeros. 
Tabla 2. La evolución del jazz y la improvisación al interior de este género musical

\begin{tabular}{|c|c|c|c|c|}
\hline Tipo de jazz & Momento & $\begin{array}{l}\text { Músicos } \\
\text { o bandas } \\
\text { destacados }\end{array}$ & Características o hechos más notorios & $\begin{array}{l}\text { Lugares y contextos } \\
\text { protagónicos }\end{array}$ \\
\hline Ragtime & 1890 & $\begin{array}{l}\text { - Scott Joplin } \\
\text { - Tom Turpin } \\
\text { - James Scott }\end{array}$ & $\begin{array}{l}\text { - Música compuesta } \\
\text { - En esencia, es una música pianística } \\
\text { - No hay improvisación }\end{array}$ & $\begin{array}{l}\text { Campamentos de trabajo, cons- } \\
\text { trucción de ferrocarriles, Nueva } \\
\text { Orleans. }\end{array}$ \\
\hline Nueva Orleans & 1900 & - Louis Armstrong. & $\begin{array}{l}\text { - Música espiritual } \\
\text { - Canciones compuestas durante el trabajo en las planta- } \\
\text { ciones (work songs). } \\
\text { - Enfrentamiento entre dos tipos de negros (americanos y } \\
\text { criollos). } \\
\text { - Tradición francesa de instrumentos de viento } \\
\text { - Ritmo cercano a la marcha europea } \\
\text { - } \text { Acentos en el primer y tercer tiempos }\end{array}$ & Nueva Orleans, Río Misisipi \\
\hline Dixieland & 1910 & $\begin{array}{l}\text { - Papa Laine } \\
\text { - Dixieland Jazz } \\
\text { Band. } \\
\text { - New Orleans } \\
\text { - Rhythm Kings }\end{array}$ & $\begin{array}{l}\text { - Menos expresivo } \\
\text { - Mayores recursos técnicos } \\
\text { - Melodías más pulidas } \\
\text { - Armonías más limpias } \\
\text { - Orquestas de blancos } \\
\text { - Se empieza a dar un mayor nivel de importancia a la im- } \\
\text { provisación. }\end{array}$ & Calles de Nueva Orleans \\
\hline Chicago & 1920 & - Bix Beiderbecke. & $\begin{array}{l}\text { - } \text { Cierre de Storyville en Nueva Orleans } \\
\text { - Migración a Chicago desde Nueva Orleans } \\
\text { - Blancos intentando imitar la música de los mejores del } \\
\text { jazz. } \\
\text { - El solista adquiere una mayor relevancia }\end{array}$ & Chicago \\
\hline Swing & 1930 & $\begin{array}{l}\text { - Count Bassie } \\
\text { - Bennie Molen } \\
\text { - Benny Godman } \\
\text { - Chu Berry } \\
\text { - Gene Krupa } \\
\text { - Cozy Cole }\end{array}$ & $\begin{array}{l}\text { - Migración de Chicago a Nueva York } \\
\text { - Formación de las Big Bands } \\
\text { - Esquema "Call and Response" } \\
\text { - El solista es más importante que en el de Chicago }\end{array}$ & $\begin{array}{l}\text { Nueva York, Ciudad de Kansas, } \\
\text { Chicago }\end{array}$ \\
\hline Bebop & 1940 & $\begin{array}{l}\text { - Dizzy Gillespie } \\
\text { - Thelonius Monk } \\
\text { - Charlie Parker }\end{array}$ & $\begin{array}{l}\text { - El intervalo más usado fue la quinta disminuida, lo que } \\
\text { generaba una notable disonancia. } \\
\text { - Frases frenéticas y nerviosas } \\
\text { - Se eliminan las notas de paso (consideradas innecesa- } \\
\text { rias). } \\
\text { - Se destaca la improvisación aunque teniendo en cuenta } \\
\text { que se presenta una frase al unísono al comienzo y al } \\
\text { final de cada tema musical. }\end{array}$ & Ciudad de Kansas \\
\hline
\end{tabular}




\begin{tabular}{|c|c|c|c|c|}
\hline Tipo de jazz & Momento & $\begin{array}{c}\text { Músicos } \\
\text { o bandas } \\
\text { destacados }\end{array}$ & Características o hechos más notorios & $\begin{array}{l}\text { Lugares y contextos } \\
\text { protagónicos }\end{array}$ \\
\hline $\begin{array}{l}\text { Cool bop } \\
\text { (Cool jazz). }\end{array}$ & \multirow{2}{*}{1950} & $\begin{array}{l}\text { - Miles Davis } \\
\text { - John Lewis } \\
\text { - Lennie Tristano }\end{array}$ & $\begin{array}{l}\text { - Expresa seguridad y equilibro gracias a la influencia de } \\
\text { los contrapuntos lineales de la música de Bach. } \\
\text { - Se destacan grandes solistas } \\
\text { - Música 'intelectual', considerada a veces fría y carente } \\
\text { de emociones. } \\
\text { - Improvisación con gran libertad }\end{array}$ & Nueva York \\
\hline Hardbop & & $\begin{array}{l}\text { - Max Roach } \\
\text { - John Coltraine } \\
\text { - Sonny Rollins }\end{array}$ & $\begin{array}{l}\text { - Es un jazz más vital } \\
\text { - Ritmos con alto grado de complejidad de estructuras que } \\
\text { le daban al género una vitalidad nunca antes conocida. } \\
\text { - Improvisación de grandes estructuras polimétricas (es } \\
\text { decir, se usan todos los materiales armónicos con liber- } \\
\text { tad). }\end{array}$ & Nueva York \\
\hline Free jazz & 1960 & $\begin{array}{l}\text { - Miles Davis } \\
\text { - Gil Evans } \\
\text { - Don Ellis }\end{array}$ & $\begin{array}{l}\text { - Amplio uso de escalas atonales } \\
\text { - Música con alto nivel de densidad } \\
\text { - Amplia extensión del sonido musical } \\
\text { - Se presenta un agotamiento de las fórmulas y los este- } \\
\text { reotipos previsibles. } \\
\text { - Uso de líneas melódicas que se cruzan y se friccionan } \\
\text { entre sí. } \\
\text { - Difiere en un alto nivel de la música europea de concierto. } \\
\text { - Hay una liberación de la armonía funcional. } \\
\text { - Alto grado de influencia de música extraeuropea (hindú, } \\
\text { japonesa, africana y árabe). Esta libertad no significa } \\
\text { desorden. } \\
\text { - La improvisación es libre de las limitaciones armónicas. } \\
\text { Se vuelve a improvisar colectivamente. }\end{array}$ & Nueva York y Alemania \\
\hline Los setenta. & 1970 & $\begin{array}{l}\text { - Gary Burton } \\
\text { - Jeremy y los Sá- } \\
\text { tiros. } \\
\text { - Tony Williams } \\
\text { - Miles Davis }\end{array}$ & $\begin{array}{l}\text { - Fusión del jazz y el rock } \\
\text { - Se decide prescindir, en algunos casos, de instrumentos } \\
\text { considerados como esenciales para el jazz. } \\
\text { - Tendencia hacia la música de cámara europea. } \\
\text { - Improvisación del jazz con ritmos del rock. Improvisacio- } \\
\text { nes sin acompañamientos. }\end{array}$ & $\begin{array}{l}\text { Aunque se desarrolla en Gran } \\
\text { Bretaña en los sesenta, adquie- } \\
\text { re en Estados Unidos un mayor } \\
\text { nivel de importancia en los se- } \\
\text { tenta. }\end{array}$ \\
\hline Los ochenta. & 1980 & $\begin{array}{l}\text { - Scott Hamilton } \\
\text { - Dexter Gordon }\end{array}$ & $\begin{array}{l}\text { - Regreso del swing } \\
\text { - Emergen jóvenes músicos que aparecen como intérpre- } \\
\text { tes de rock o de fusión. } \\
\text { - Regreso notable del Bebop }\end{array}$ & Nueva York \\
\hline
\end{tabular}

Fuente: elaboración de los autores, a partir de Berendt (1994). 
Uno de los tipos de jazz que más ha aprovechado las virtudes de la improvisación es el 'free jazz'. En sus orígenes, sin embargo, quizás por sus sonidos estridentes característicos y su alto grado de libertad atonal $^{1}$, este no fue muy bien recibido por parte de la crítica. Sin embargo, la falta de aceptación de nuevas propuestas sucedió también antes en múltiples casos en el mundo de la música, incluso en el contexto de la música clásica. Un ejemplo de esto lo constituyen las críticas de Johann A. Hiller ${ }^{2}$ a las 'crudezas de Bach' o las devoluciones que recibió Mozart de la primera impresión de sus cuartetos, debido a que las disonancias plasmadas alli fueron consideradas como un 'error de impresión' de las planchas. De hecho, la música de Beethoven llegó también a ser considerada, en algún momento, como 'chillante e incoherente'.

Pese a no ser bien recibido por todos los actores del mundo de la música, el concepto de improvisación está presente en los diferentes procesos musicales (Lortat-Jacob, 1987). Es posible observarlo tanto en la propia creación de una obra como en su puesta en escena en una presentación. En efecto, en el proceso de composición se requiere, de cualquier modo, que quien crea la pieza realice un ejercicio de improvisación para definir la forma rítmica, armónica y melódica de la misma. Así, esta emerge gradualmente, a través de las ideas, para luego ser plasmada e interpretada de manera deliberada por el propio compositor o cualquier otro músico (Schoenberg, 1950). El músico que está en un escenario, sin embargo, tiene ciertos patrones y elementos definidos que permiten, de algún modo, que su creación emerja de manera espontánea en un momento determinado (De Contreras, 2005).

Así, en general, es posible afirmar que la improvisación es tan antigua como la música misma. Aunque este concepto es tan amplio que, en ocasiones, se

1 "La atonalidad (del griego a: 'sin' y el español tonalidad) es el sistema musical que carece de toda relación de los tonos de una obra con un tono fundamental y de todos los lazos armónicos y funcionales en su melodía y acordes, sin estar sujeto a las normas de la tonalidad". Ver https://es.wikipedia.org/ wiki/Atonalidad.

2 Músico y dramaturgo alemán considerado uno de los padres de la ópera. torna impreciso (Berendt, 1994), existen autores que la definen como una "combinación espontánea basada en reglas de elementos para crear nuevas secuencias que son apropiadas para un momento dado en un contexto dado" (Berkowitz, 2010: xix). En el jazz, en particular, la improvisación se desarrolla en varios niveles, de modo que, en un determinado momento, los demás miembros del grupo pueden estar improvisando, mientras acompañan al solista principal, quien también lo hace. Esto se da, en lo fundamental, porque los músicos que hacen el acompañamiento armónico o rítmico pueden realzar las ideas de quien hace el solo. De hecho, ellos están en capacidad de proponer ideas que el solista puede llegar a desarrollar durante su ejecución (De Contreras, 2005).

Dado que el concepto de improvisación no es del todo preciso y unívoco, existen posturas que afirman que esta se presenta de forma natural o emergente. Así, el individuo toma la información que ingresa a sus sentidos en un momento y lugar determinados y, posteriormente, la procesa y exterioriza de acuerdo con las habilidades de las que dispone (Nachmanovitch, 2004). Para hacerlo, el sujeto se vale de una mezcla muy propia de sus conocimientos, emociones, gustos, aptitudes y actitudes. Con todo, tal y como sucede en el contexto de la estrategia entre la mirada deliberada y la emergente, en el sentido de rescatar la complementariedad o incluso la secuencialidad o circularidad entre ambas (Mintzberg, 1978, 1990b; Montoya, 2010), existe también una postura al interior del mundo de la música que valora la creación de arreglos previamente definidos, es decir, una estructura deliberada, en la medida en la que esta brinda la confianza necesaria al músico solista de saber qué están tocando sus compañeros y, de este modo, encontrar un más tranquilo contexto para definir el alcance de su improvisación (Berendt, 1994). De hecho, al momento de prepararla, es usual que se establezca el orden de los solos improvisados y su longitud durante los ensayos (De Contreras, 2005).

Otro gran aspecto identificado, que permite el establecimiento de una discusión, está ligado a la composición y la improvisación. Así, por ejemplo, mientras autores como Nachmanovitch (2004) afirman 
que "un compositor que escribe está improvisando al comienzo y luego toma los productos de dicha improvisación y los refina" (p. 16), otros, desde un punto de vista europeo, indican que la composición significa la "exclusión de la improvisación" (Berendt, 1994: 238). Desde esta última perspectiva, entonces, la gran diferencia entre composición e improvisación está en que la música compuesta, como la europea, puede ser tocada por cualquier intérprete que tenga la habilidad técnica e instrumental para hacerlo. Por el contrario, la improvisada solo puede ser tocada por su creador. De este modo, puede que quien intente imitarla tenga una técnica mejor y que, a pesar de esto, no tenga la capacidad de reproducirlo exactamente (Berendt, 1994: 239).

En este punto se hace evidente entonces la desconfianza que pueden tener quienes interpretan música clásica, frente a las técnicas de improvisación propias del jazz, por ejemplo. Sin embargo, esta posición parecería desconocer que los inicios de la música clásica estaban también marcados por dichas técnicas (Thomas, 2015). En realidad, la improvisación basada en el jazz no se limita a la ejecución fría y calculada de un tema musical previamente escrito, sino que lo enriquece llenándolo de emociones que generan empatía con el público que lo escucha. De igual manera, si un músico improvisa, acompañado de un conjunto de colegas, se ve obligado a escucharlos, a reaccionar y a predecir sus movimientos. Así, es posible que para poder improvisar se requiera un nivel de entendimiento más elevado al que se tiene cuando se ejecuta algo establecido con anterioridad (Schober \& Spiro, 2014).

Lo indicado en esta sección, haciendo uso de un pensamiento metafórico - de amplio espectro en el desarrollo del campo de los estudios organizacionales (Barnett, 1996; Cornelissen, 2005; Cornelissen et al., 2008; Grant \& Oswick, 1996; Heracleous \& Jacobs, 2011; Hill \& Levenhagen, 1995; Inns, 2002; Letiche \& van Uden, 1998; Manning, 1979; Morgan, 1980; Örtenblad et al., 2013)—, procura entonces establecer una base para la contribución que se espera realizar, a través de esta investigación, a la serie de trabajos que han abierto el espacio, en particular, a una importante serie de conversaciones que ponen en relación aspectos como la improvisación, la música, la administración, las organizaciones y la estrategia (Arshad, 2011; Barrett, 1998; Duxbury, 2014; Hatch \& Weick, 1998; Kamoche et al., 2002, 2003; Mantere, et al., 2007; Meyer et al., 1998; Patrick, 2008; Weick, 1998). De hecho, existen razones para pensar que la citada metáfora vale la pena y su utilización tiene sentido en trabajos como este (ver tabla 3).

Tabla 3. Algunos elementos propios del mundo de la música y su correlato metafórico en el contexto organizacional

\begin{tabular}{|l|l|l|l|}
\hline $\begin{array}{c}\text { Concepto } \\
\text { musical }\end{array}$ & \multicolumn{1}{|c|}{$\begin{array}{c}\text { Percepción desde la } \\
\text { música europea }\end{array}$} & \multicolumn{1}{|c|}{ Percepción desde el jazz } & $\begin{array}{c}\text { Correlato metafórico en el contexto } \\
\text { organizacional }\end{array}$ \\
\hline Partitura & Instrucción de modelo a seguir & $\begin{array}{l}\text { Poco usada. Completamente diferente a la } \\
\text { partitura clásica. Es en esencia un referente. }\end{array}$ & Estrategia deliberada - planeación estratégica. \\
\hline Composición & Ausencia de improvisación & Improvisación durante la ejecución & $\begin{array}{l}\text { Estrategia deliberada (percepción europea) / } \\
\text { estrategia emergente (percepción del jazz). }\end{array}$ \\
\hline Improvisación & Ausencia de composición & Creación espontánea de secuencias & Estrategia emergente \\
\hline Arreglo & $\begin{array}{l}\text { Definición de patrones para la eje- } \\
\text { cución }\end{array}$ & Definición de patrones para la ejecución & $\begin{array}{l}\text { Desde la perspectiva de la música europea } \\
\text { estaría el 'plan' / desde la perspectiva del jazz } \\
\text { sería el 'patrón'. }\end{array}$ \\
\hline Melodía & $\begin{array}{l}\text { Líder absoluto de la obra. A partir } \\
\text { de su movimiento, los instrumen- } \\
\text { tos armónicos y rítmicos la siguen. }\end{array}$ & $\begin{array}{l}\text { Puede recibir aportes de los instrumentos ar- } \\
\text { mónicos o rítmicos. De igual manera, puede } \\
\text { influenciarlos. Se adapta al ambiente. }\end{array}$ & $\begin{array}{l}\text { Desde la música europea: liderazgo transac- } \\
\text { cional en las estrategias deliberadas / desde el } \\
\text { jazziderazgo transformacional, que escucha } \\
\text { e influye. Puede aplicarse a ambos tipos de } \\
\text { estrategia. }\end{array}$ \\
\hline Armonía & $\begin{array}{l}\text { Acompañante por excelencia de } \\
\text { la línea melódica. No improvisa, } \\
\text { sigue estructuras preestablecidas. }\end{array}$ & $\begin{array}{l}\text { Acompañante. Aunque tiene estructuras esta- } \\
\text { blecidas, improvisa al tiempo que la melodía. } \\
\text { Puede influir y es influida por la melodía. }\end{array}$ & $\begin{array}{l}\text { Música clásica: seguidor del líder, estrategia } \\
\text { deliberada / desde el jazz influye y es influido. } \\
\text { Estrategia emergente y deliberada. }\end{array}$ \\
\hline
\end{tabular}

Fuente: elaboración de los autores, a partir de Berendt (1994). 
Finalmente, podría pensarse que, así como los músicos se interrelacionan de diversas formas, marcadas por lógicas y prácticas tanto deliberadas como emergentes, la organización y sus miembros podrían llegar a vincularse con la idea de un sistema que requiere no solo establecer un rumbo de acción y tratar de seguirlo, sino también y, frecuentemente, adaptarse de manera dinámica, flexible y evolutiva a las diversas situaciones que deben enfrentar. Así, usando un lenguaje metafórico, podría considerarse que cuando no necesariamente se tiene una 'partitura' a seguir, pero es necesario 'interpretar' pues, por ejemplo, se está ya frente a un 'auditorio', no hay otro camino que improvisar e ir marcando un rumbo a medida que se 'interpreta una obra'. De cualquier manera, para poder hacer algo así, parecería necesario contar con una cierta preparación y disposición.

\section{Metodología}

En este trabajo comprendemos la metodología como una "combinación de técnicas usadas para investigar una situación específica" (Easterby-Smith, Thorpe, \& Jackson, 2012: 18), la cual se compone principalmente de tres dimensiones que soportan el ejercicio de indagación de una realidad particular. Estas son: 1) la(s) estrategia(s) de investigación, 2) los métodos y 3) los tipos de datos utilizados (Taylor \& Sinha, 2006: 8). Este componente esencial, para cualquier estudio científico, está directamente vinculado tanto con los supuestos epistemológicos y ontológicos que asumen los investigadores, como con los métodos y técnicas considerados para recolectar los datos, procesarlos y analizarlos (Easterby-Smith et al., 2012).

Nuestro estudio se inscribe en la aproximación cualitativa (Denzin \& Lincoln, 2011). Desde esta tradición se desarrolló el diseño del estudio (Creswell, 2014). En lo fundamental, la investigación cualitativa se aproxima a la realidad con el fin de:

Comprender, describir y algunas veces explicar los fenómenos sociales 'desde adentro' en un número de formas distintas (...) analizando experiencias de individuos o grupos, (...) interacciones y comunicaciones cuando ocurren [y] (...) documentos (textos, imágenes, filmes o música) o trazos similares de experiencias e interacciones (Flick, 2007: ix).

Según lo anterior, el trabajo se llevó a cabo no solo considerando los supuestos ontológicos, epistemológicos y metodológicos asumidos por los investigadores (Guba \& Lincoln, 1994: 107), los cuales se vinculan con el paradigma interpretativista (Burrell \& Morgan, 1979; Yanow \& Schwartz-Shea, 2006), sino también, en particular, teniendo en cuenta la naturaleza de la problemática abordada (es decir, el desarrollo de estrategias emergentes) (Mintzberg \& Waters, 1985). Ésta invita más que a la realización de un estudio transversal, de prevalencia o vertical (cross sectional), concentrado en un momento específico del tiempo y vinculado usualmente con la tradición positivista (Easterby-Smith et al., 2012: 67), a la implementación de un estudio longitudinal (Forgues \& Vandangeon-Derumez, 2007; Miller \& Friesen, 1982; Pettigrew, 1989; Saldaña, 2003). Esto a partir de la necesidad de investigar, específcamente, un proceso que se desarrolla a través del tiempo, tal y como se requiere cuando se pretende indagar acerca del tipo de estrategias en las que se interesa este trabajo (Mintzberg, 1978) y, en general, acerca de buena parte de los demás fenómenos propios de campos como el de la estrategia (Dess \& Lumpkin, 2005; Hutzschenreuter \& Kleindienst, 2006; Styhre, 2002) y, más ampliamente, el de los estudios organizacionales (Helms-Mills, Dye, \& Mills, 2009; Ployhart \& Vandenberg, 2010).

Por otra parte, considerando 1) las tres dimensiones - mencionadas arriba- que dan forma a la metodología (Taylor \& Sinha, 2006), 2) los elementos de base que se acaban de indicar y 3) las actividades necesarias para poder cumplir con los objetivos de este trabajo, este estudio se desarrolló teniendo en cuenta los siguientes aspectos:

\subsection{Estrategia de investigación}

La estrategia de investigación desarrollada para este trabajo fue el análisis situacional. Esta estrategia, propuesta por Alvesson (1996), se concentra en el estudio detallado de situaciones específicas en el contexto organizacional, como las juntas directivas, desarrollando una serie de labores que son afines a 
la lógica propia de la investigación etnográfica (Van Maanen, 2011; Ybema, Yanow, Wels, \& Kamsteeg, 2009). Tiene como fin, en lo esencial, obtener el conocimiento del fenómeno estudiado, accediendo a una o varias situaciones particulares de la organización, propia(s) de su dinámica cotidiana.

Para hacer esto, el análisis situacional se concentra en estudiar, en lo fundamental, cinco variables básicas. Estas son: 1) el acto, es decir lo que sucede en la situación estudiada; 2) los agentes, o sea los actores que hicieron parte del acto; 3) la escena, en otras palabras, el contexto en el que se desarrolló el acto; 4) el propósito, o los objetivos que dieron lugar al acto, y 5) la acción en sí, la cual hace referencia a cómo se desarrolló el acto.

Estos elementos fueron considerados en las situaciones objeto de estudio. Dichas situaciones fueron, en atención a la problemática estudiada, las reuniones de la Junta Directiva de una organización. Esta fue seleccionada no solo por su relevancia sino, en particular, por la posibilidad que se abrió de acceder en ella a estos escenarios privilegiados de estudio (Girin, 1989). Así, fue posible asistir a nueve reuniones de este tipo realizadas a lo largo de un año. En estos espacios se discutieron, como es usual, los aspectos más relevantes y profundos de la organización y emergieron, de algún modo a la manera de "patrones al interior de una corriente de decisiones" (Mintzberg, 1978: 935), sus principales estrategias.

\subsection{Métodos}

Considerando, en particular, 1) la estrategia de investigación implementada, 2) la aproximación cualitativa asumida, 3) el paradigma interpretativista en el que se inscribe el trabajo y 4) la naturaleza de la problemática estudiada, se privilegió para nuestro trabajo el uso de la observación (Katz, 2015; Lofland, Lofland, Snow, \& Anderson, 2006). Se participó así en cada una de las juntas directivas, tomando notas de las mismas y grabando de principio a fin el audio de cada una de estas situaciones (Gordon, 2013). También fueron utilizados el análisis documental (Glenn, 2009; Mogalakwe, 2006), específicamente de textos propios de la organización y de su contexto, y la realización de nueve entre- vistas semiestructuradas (Alvesson, 2011; Alvesson \& Ashcraft, 2012; Kvale, 2007) tanto a expertos (uno del mundo de la estrategia empresarial, en la práctica, a la cabeza de un gran grupo empresarial, y tres del ámbito musical) como, en lo fundamental, a cinco testigos privilegiados (miembros de la Junta Directiva de la organización) (Quivy \& Van Campenhoudt, 2006). Estas también fueron grabadas en audio digital.

\subsection{Tipos de datos utilizados}

Los métodos utilizados permitieron recabar datos de tipo cualitativo, específicamente los siguientes:

1. El audio correspondiente a las juntas directivas y las entrevistas (en total: 1132,29 minutos).

2. La transcripción de estos audios, es decir, páginas de texto correspondientes a los mismos (en total: 344 páginas). Para realizar esta labor, en particular, se utilizó el protocolo que con este fin fue propuesto por Sanabria (2014).

3. Las notas tomadas durante el desarrollo de las juntas directivas a las que se asistió.

4. Los documentos de la organización y del contexto de la misma que fueron recabados durante el trabajo de campo de la investigación.

5. La transcripción de las entrevistas realizadas a cinco miembros de la Junta Directiva de la organización estudiada.

6. La transcripción de la entrevista realizada al reconocido empresario y experto en estrategia organizacional, el Señor Jean Claude Bessudo, dueño de la organización Aviatur y autor del libro Improvisación estratégica (Bessudo, 2007).

7. La transcripción de la entrevista realizada a tres músicos de jazz expertos.

Estos datos resultan entonces de -y son coherentes con- la aproximación asumida, la estrategia de investigación implementada y los métodos selec- 
cionados para realizar el trabajo. Estos provienen también del interés por comprender y explicar los fenómenos haciendo una inmersión directa en el terreno y observando, de manera longitudinal, lo que sucede en este. Este tipo de material posee una gran riqueza interpretativa, la cual no solo es el resultado del valor intrínseco de los datos recolectados, sino también, en particular, del hecho mismo de que estos provienen de un contacto profundo de quienes investigan con el fenómeno estudiado (Alvesson \& Sköldberg, 2009).

\subsection{Procedimiento realizado para recolectar los datos}

\subsubsection{Observación de las reuniones de la Junta Directiva}

En primer lugar, se contactó al director general de la organización ${ }^{3}$, una corporación sin ánimo de lucro que fue fundada hace casi sesenta años. Esta trabaja en la restitución de los derechos de un segmento poblacional específico al que estos le han sido vulnerados de algún modo. En 2014, esta organización contaba con setenta y ocho trabajadores, de los cuales el $16 \%$ pertenecía al equipo psicosocial, el $25 \%$ cumplía labores de servicios generales, el $21 \%$ eran coordinadores, el $26 \%$ realizaba labores administrativas y el $12 \%$ eran educadores. Estos, en conjunto, se encontraban distribuidos en tres unidades de servicio, siguiendo esta distribución: $75 \%$ en la primera unidad, $14 \%$ en dos sedes complementarias en la ciudad de Bogotá (Colombia) y $11 \%$ en la división administrativa.

Se tramitó ante esta organización la autorización correspondiente para que 1) fuera posible presenciar las reuniones de la Junta Directiva, 2) se permitiera la grabación en audio de las mismas y 3) fuera posible acceder posteriormente a estos registros, transcribirlos, analizarlos y difundirlos parcialmente. Esta autorización fue lograda bajo el estricto acuer-

3 Se habla aquí de manera genérica de la organización que fue objeto de estudio, sin dar su nombre propio, para preservar el derecho al anonimato tanto de esta, como un todo, como de los diferentes participantes de la investigación (Vainio, 2013). do de mantener el anonimato tanto de la organización como de sus miembros (Vainio, 2013).

Se asistió luego a las reuniones de la Junta Directiva a lo largo de 2014. Fue posible así, de acuerdo a lo previsto, contar con las grabaciones de audio de las sesiones realizadas durante ese año. Como se indicó antes, en total, se asistió a nueve reuniones de la Junta. Los audios producidos fueron debidamente transcritos. Hay que indicar, sin embargo, que ni en enero ni en marzo se realizaron estas reuniones y que, por problemas técnicos, no fue posible contar con el audio de la reunión del mes de mayo.

Las reuniones de la Junta Directiva se llevaron a cabo en la sede de la Unidad Administrativa el primer miércoles de cada mes, exceptuando enero y marzo. Durante las mismas se presentaron los resultados mensuales en materia financiera y social $y$, por supuesto, se analizaron los temas más relevantes de la organización y se tomaron decisiones esenciales para la misma.

Alrededor de las diferentes reuniones realizadas, considerando los objetivos de la investigación, se llevaron a cabo las siguientes actividades:

- Identificación de los participantes (cargo, profesión y perfil general).

- Establecimiento del nivel de asistencia de los mismos.

- Determinación del rol de cada actor dentro de la Junta, así como de su nivel de participación.

- Discernimiento básico de los cinco componentes propios del análisis situacional.

Las reuniones de junta directiva siguieron siempre una estructura preestablecida (orden del día). Esta se desarrolló usualmente de la siguiente manera: verificación del quórum, lectura y aprobación del orden del día, lectura y aprobación del acta anterior, informe del Comité Financiero, informe de Dirección General y varios. Como es usual en escenarios de este tipo, al inicio de las reuniones el presidente de la Junta Directiva hacía la lectura del orden del día y 
preguntaba a los demás miembros si se aprobaba o no. Posteriormente, se realizaban diversos comentarios generales alrededor de los primeros puntos. Se buscaba tratar siempre cada tema por separado, sin embargo, en algunas ocasiones, se mezclaban ciertos puntos por iniciativa de algún participante.

Las reuniones se prolongaban normalmente hasta que se hubiera tratado la totalidad de los temas previstos. Al final, era común que se trataran múltiples asuntos propuestos por los diferentes asistentes. Estos, por lo general, no estaban previstos, salvo, de manera general, en el último punto del orden del día (varios). Las sesiones duraron en promedio dos horas. En este tiempo era usual que se alcanzara a tratar los temas considerados como de mayor relevancia para la organización.

\subsubsection{Entrevistas}

Para complementar el trabajo de campo realizado, se consideró pertinente llevar a cabo nueve entrevistas. Cinco de estas se realizaron con miembros de la Junta Directiva de la organización. Esto con el fin de identificar su representación acerca de lo vivido por ellos en los espacios estudiados. La elección de estos participantes se basó en su jerarquía y en la preponderancia identificada en el contexto de la Junta, medida, en lo fundamental, por su nivel de participación, influencia y poder de decisión.

Por otra parte, como una actividad básica para enriquecer la comprensión de los hallazgos obtenidos a partir de la realización del trabajo de terreno, se estimó pertinente contactar al reconocido empresario y experto en estrategia - aunque desde una perspectiva heterodoxa (Bessudo, 2007)— Jean Claude Bessudo. Esto dada su amplia y exitosa trayectoria, su prestigio y, en particular, su robusta defensa y vivencia de la improvisación en el contexto organizacional. De hecho, su libro Improvisación estratégica fue una referencia básica para el presente trabajo.

Por último, dado que para el jazz, una metáfora explicativa altamente utilizada en el contexto organizacional (Barrett, 1998; Hatch, 1999; Humphreys, Ucbasaran, \& Lockett, 2012; Kamoche et al.,
2003; Meyer et al., 1998), la improvisación juega un rol muy destacado (ver sección 2.4.), se consideró necesario entrevistar también a tres músicos expertos de este género. Estas entrevistas tuvieron una gran importancia para el enriquecimiento de nuestra labor interpretativa, dado que, a lo largo de su ejercicio profesional, ellos han logrado comprender ampliamente el rol y la importancia de la improvisación en su actividad cotidiana $y$, a partir de este conocimiento experto, también, eventualmente, en otros contextos.

El trabajo de terreno comenzó a inicios de 2014 y culminó el primer semestre de 2016. El año 2015 se usó de manera central para la profundización de la revisión de literatura y la continuación en el avance de los primeros ciclos de codificación y análisis del material empírico recabado. El trabajo, como un todo, se dio por terminado a finales de julio de 2016 .

\subsection{Técnicas para el procesamiento y análisis de los datos}

Para el procesamiento de los datos, en particular, de los audios, de las notas tomadas, de las transcripciones de las sesiones de la Junta Directiva y de las entrevistas realizadas, se recurrió al uso del software Atlas.ti (v.7). Antes de hacer esto, los audios fueron integralmente transcritos (Davidson, 2009; Hennink \& Weber, 2013), siguiendo el protocolo antes anunciado, en documentos elaborados haciendo uso de Microsoft Word.

Para la codificación del material empírico recolectado se usó la técnica del análisis temático (Guest, MacQueen \& Namey, 2012). Esto implicó, en general, la revisión detallada, sistemática y rigurosa del material, la identificación al interior de este de elementos comunes y el etiquetado de los mismos. Para esta última actividad fueron consideradas inicialmente las categorías establecidas por la estrategia del análisis situacional (ver sección 3.1.). Esto, por supuesto, no implicó desechar diversas variables emergentes del propio análisis, las cuales fueron consideradas como de importancia para el trabajo.

Una vez determinadas las categorías, se establecieron relaciones de sentido entre las mismas. Esto con 
el fin de acercarse a la construcción de aspectos teóricos, de carácter más general, que permitieran dar un sentido global al material empírico, proveer explicaciones del mismo y, a través de ello, obtener los resultados básicos del trabajo de investigación. Esto a partir de los hechos observados y de la problemática y el objetivo a los que se pretendía responder. Este ejercicio fue realizado de manera independiente, aunque sobre las bases comunes mencionadas, por cada uno de los investigadores. Esto implicó, en total, tres ciclos de codificación. Luego de esto se integraron los resultados de los análisis y se elaboró este artículo (en tanto informe final).

\section{Resultados}

En este apartado se presentan los resultados obtenidos a partir del trabajo de campo realizado. Estos dan cuenta, en particular, de cuatro temas prevalentes a lo largo de las narrativas, a saber: 1) una 'voz'4 (lo financiero) y 2) su correspondiente 'vocalista'5 (el director financiero), 3) una marcada 'intensidad' 6 (lo operativo) y 4) el énfasis en dos 'tiempos' (el presente y el pasado). Ellos fueron marcados por el 'ritmo'7 que los asuntos emergentes, propios del día a día, fueron imponiendo.

4 "La voz es un instrumento de viento, componente de la música que se crea mediante las cuerdas vocales de una persona. La voz humana se puede utilizar de distintas maneras en la música, por ejemplo el canto". Ver https://es.wikipedia. org/wiki/Voz_(m\%C3\%BAsica).

5 "Se le llama cantante o vocalista, al artista que produce con su voz sonidos melodiosos (...) suele acompañarse de música instrumental". Ver https://es.wikipedia.org/wiki/Cantante.

6 "La intensidad en música es la cualidad que diferencia un sonido suave de un sonido fuerte. Depende de la fuerza con la que el cuerpo sonoro sea ejecutado y de la distancia del receptor de la fuente sonora. Se trata de una de las cuatro cualidades esenciales del sonido articulado junto con la altura, la duración y el timbre". Ver https://es.wikipedia.org/ wiki/Intensidad_(m\%C3\%BAsica).

7 En el contexto musical el ritmo: "Es la pauta de repetición a intervalos regulares y en ciertas ocasiones irregulares de sonidos fuertes o débiles, y silencios en una composición. El ritmo está relacionado con cualquier movimiento que se repite con regularidad en el tiempo, en la música se lo divide por medio de la combinación de sonidos y silencios de distinta duración". Ver https://oscrove.wordpress.com/teoriamusical/los-elementos-de-la-musica/.

\subsection{La voz (lo financiero) y su correspondiente vocalista (el director financiero)}

Lo financiero constituyó 'la voz' recurrente a lo largo de las diferentes juntas directivas observadas, en las entrevistas realizadas y los documentos recabados. Las preocupaciones giraron, en particular, alrededor de la desfavorable situación financiera que la organización atravesaba y el riesgo que esto implicaba para la misma ${ }^{8}$. El encargado de transmitir estos mensajes, el 'vocalista' principal, fue, en lo fundamental, el director financiero:

La situación es dramática porque con ingresos de 134 millones de pesos en esta división no podemos tener gastos de 165 millones ${ }^{9}$ (...). Si esto es así, nos vamos a quebrar en un par de meses (reunión de Junta Directiva: director financiero, febrero de 2014 , transcripción $n^{\circ}$. 1, p. 2).

La cifra de deudores es demasiado alta para lo que nosotros deberíamos manejar (...). Hay retrasos de una de nuestras fuentes de recursos (...). ¡Hay retrasos entonces por todos lados! (reunión de Junta Directiva: director financiero, abril de 2014, transcripción $n^{\circ} .2$, p. 9).

Tenemos un aumento de contratos y convenios de $10 \%$, pero los costos y gastos (...) tienen un aumento del 18\%. ¡A hí hay un problema serio! (reunión de Junta Directiva: director financiero, junio de 2014, transcripción n. 3, p. 16-17).

8 En los diferentes fragmentos que se insertan de aquí en adelante, los cuales emergen del proceso analítico realizado con base en el material empírico recabado, se han remplazado los nombres de organizaciones y de personas por seudónimos o pronombres o, cuando se estimó que esto no cambiaba el sentido de la oración, ellos fueron eliminados. Además, todos los cargos se escribieron en género masculino. Esto a pesar de que múltiples participantes en el estudio fueron mujeres. Lo anterior, se hizo con el fin preservar el anonimato prometido a la organización y sus miembros y evitar que su identidad fuera revelada directa o indirectamente (p. ej., por triangulación de datos por parte del lector).

9 Cada vez que se habla de cifras monetarias en este documento se hace alusión a pesos colombianos (COP). 
La pérdida acumulada va en 139 millones de pesos y depreciación son solo 57 [millones], o sea que ahí tenemos un problema de caja de 80 millones (reunión de Junta Directiva: director financiero, julio de 2014, transcripción $n^{\circ} .4$, p. 6).

Tenemos ahí el acumulado de 146 [millones] de pérdidas del ejercicio, pero digamos, patrimonialmente es una organización sólida, pero si no logramos revertir el tema de las pérdidas mensuales, pues en muy pocos meses vamos a estar con un déficit de caja y juno se quiebra es por la caja y no por el patrimonio! (reunión de Junta Directiva: director financiero, agosto de 2014, transcripción $n^{\circ}$. 5, p. 13).

Esta división presenta un déficit de \$8.157.737 (reunión de Junta Directiva: coordinador financiero, octubre de 2014, transcripción $n^{\circ} .7$, p. 2).

El acumulado del año nos permite encontrar una pérdida de \$104.134.849 (...) la operación de septiembre también fue pérdida (reunión de Junta Directiva: coordinador financiero, noviembre de 2014, transcripción $n^{\circ}$. 8, p. 2).

Estos aspectos, de hecho, no concentraron únicamente los 'solos'10 interpretados por el director financiero - en calidad de 'solista'11_, sino las propias interacciones entre los miembros de la Junta,

10 En la música un 'solo' es una "composición o parte de ella que canta o toca una persona sola" http://dle.rae. es/?w=diccionario.

11 Un 'solista' es una "persona que ejecuta un solo de una pieza vocal o instrumental". Ver http://dle.rae.es/?w=diccionario. en las que se escuchaban otras voces dando así a 'la interpretación' 12 ciertos 'matices' ${ }^{13}$ :

- Miembro de la Junta Directiva: perdón, ¿vamos en el 2014 con una pérdida de 113 millones?

- Director financiero: exacto (...) y este año tenemos un déficit de caja de 70 millones de pesos (reunión de Junta Directiva: conversación entre miembros de la Junta Directiva, junio de 2014, transcripción $n^{\circ}$. 3, p. 18).

- Director financiero: eso sigue igual, no hay cambios en los costos de este programa, que es, digamos, en donde se está presentando una pérdida que, en vez de pérdida, debería ser utilidad ¿cierto?

- Coordinador financiero: sí señor.

- Director financiero: imagino que el plan de choque se va a referir a eso, a controlar esas cosas en esta división (reunión de Junta Directiva: conversación entre varios miembros de la Junta Directiva, julio de 2014, transcripción $\mathrm{n}^{\circ} .4$, p. 2).

En estas interacciones se destaca también la presencia de múltiples representaciones simultáneas, por ejemplo, frente a las mismas cifras, conformando una suerte de 'polifonía'14. Esto dependiendo del énfasis que cada actor hacía en las mismas:

12 Se considera que "la interpretación musical es el arte de ejecutar en un instrumento obras musicales de compositores de distintos períodos y estilos, conjugando el conocimiento del lenguaje musical, el dominio técnico y sonoro del instrumento y la sensibilidad, expresión y entrega del intérprete". Ver https://www.uach.cl/admision/principal/va1divia/ interpretacion-musical

13 En el contexto musical los 'matices' son "la intención, el color o dinámica que se da a la música. Son las diferentes gradaciones que se puede dar a una [sic] sonido o frase musical. Son las dinámicas que se aplican para enriquecer el hecho musical". Ver https://oscrove.wordpress.com/teoriamusical/los-elementos-de-la-musica/.

14 En el mundo musical una 'polifonía' corresponde al "conjunto de sonidos simultáneos en que cada uno expresa su idea musical, pero formando con los demás un todo armónico". Ver http://dle.rae.es/?w=diccionario. 
- Miembro de la Junta Directiva: ¡Ah! entonces ya está actualizado el patrimonio.

- Director financiero: sí, está ya actualizado. Entonces tenemos un patrimonio solido de diez mil millones de pesos contra un pasivo de trescientos millones, podemos estar tranquilos.

- Miembro fundador: es una buena noticia, inunca me imaginé una organización así de maravillosa!

- Director de la organización: de todas maneras tenemos que fortalecer la operación.

- Director financiero: hay que fortalecer los ingresos y manejar el tema de gasto en el que he insistido (reunión de Junta Directiva: conversación entre varios miembros de la Junta Directiva, febrero de 2014, transcripción $\mathrm{n}^{\circ}$. 1, p. 7).

En el marco de esta 'polifonía', dada en determinados momentos al interior de las situaciones estudiadas, cuando algunos otros actores procuraron insertar, por sus propias representaciones, temas que consideraban importantes, el director financiero hacía resaltar su voz frente a la de los demás. Con esto lograba retornar la atención del grupo a lo que, a su parecer, era lo más importante (los asuntos económicos):

- Director de la organización: sí y, a mí me gustaría que antes de que entráramos a hablar de lo de la comunidad y de lo que se está haciendo, hablemos un poquito de este otro programa.

- Director financiero: ¡ah! ok, ipero sigamos con los estados financieros! (reunión de Junta Directiva: conversación entre varios miembros de la Junta Directiva, abril de 2014, transcripción $n^{\circ} .2$, p. 7).

De este modo, se observó un aspecto que resaltó, a lo largo de las reuniones estudiadas: una voz (lo financiero) y un vocalista destacado (el director fi- nanciero). Esto, sin embargo, no estaba vinculado necesariamente con el protagonismo del último actor en cuanto tal, sino, en lo fundamental, con la importancia que los diferentes individuos asignaban al difícil resultado que presentaba la organización en esta materia y que afectaba su operación, lo que daba una mayor intensidad a este asunto. Esto, como se ha evidenciado, a pesar de que la organización contaba con un patrimonio robusto que respaldaba su perdurabilidad, al menos a mediano plazo.

\subsection{Una marcada 'intensidad' (lo operativo) y un énfasis en dos 'tiempos' (el presente y el pasado)}

Como se ha indicado, en las situaciones estudiadas, fue posible observar un énfasis en lo operativo, inducido, en lo fundamental, por las preocupaciones en materia financiera y la importancia que estos asuntos fueron adquiriendo en la escala de prioridades de los actores encargados de construir de manera conjunta la 'melodía' 15 que animaba sus diferentes encuentros. Esto los condujo a preocuparse más por el tiempo presente y el pasado, así como por asuntos muy concretos propios del cotidiano, que por el futuro y por nuevos retos que podrían tener una mayor envergadura; en otras palabras, ese fenómeno los llevó a descuidar cuestiones que, en el contexto de la estrategia, son consideradas como verdaderos protagonistas, tales como la existencia de un 'propósito estratégico' (Hamel \& Prahalad, 1989) y, más ampliamente, de un 'pensamiento estratégico' que, entre otras características, vincula siempre el pasado y el presente con el futuro (Liedtka, 1998: 123):

Ahí en esta división hay varias cosas que nos afectan la caja (...). Tuvimos que hacer también muchas cosas que se habían aplazado (reunión de Junta Directiva: director de la organización, abril de 2014, transcripción $n^{\circ} .2$, p. 8).

15 "Una melodía es una sucesión de sonidos que es percibida como una sola entidad. Se desenvuelve en una secuencia lineal, es decir a lo largo del tiempo, y tiene una identidad y significado propio dentro de un entorno sonoro particular". Ver https://es.wikipedia.org/wiki/Melod\%C3\%ADa. 
Ya saben que el 15 de diciembre se terminó el contrato con esta entidad pública y, aunque habían dicho que iban a hacer una prórroga, la Oficina Jurídica de Bogotá [Colombia], solamente la regional de Bogotá, consideró que había que hacer un contrato nuevo (reunión de Junta Directiva: director de la organización, febrero de 2014, transcripción $n^{\circ}$. 1, p. 19).

En el mes de mayo la organización recibió la visita del Icontec [Instituto Colombiano de Normas Técnicas y Certificación], para la renovación del certificado de calidad con la norma ISO 9001, en la cual solo se tuvieron cuatro no conformidades menores y tuvimos varios reconocimientos (...). Se recomendó la renovación de la certificación (reunión de Junta Directiva: director de la organización, junio de 2014, transcripción $n^{\circ}$. 3 , p. 14).

Aquí, en mantenimiento, nosotros tenemos un problema y es que a la entidad pública que nos vigila en esta materia a cada rato se le ocurre que tenemos que hacer remodelaciones (reunión de Junta Directiva: director de la organización, julio de 2014, transcripción $n^{\circ} .4$, p. 13).

Esta entidad pública, con la que contratamos, siempre se demora en pagar entre el 15 y el 20 del mes siguiente, pero es que ayer si fue más demorado (reunión de Junta Directiva: director de la organización, febrero de 2014, transcripción $\mathrm{n}^{\circ} .1, \mathrm{p} .6$ ).

Ciertos actores, sin embargo, soportados en su intuición, plantean la necesidad de ir más allá de estas preocupaciones cotidianas, de cambiar la melodía, de hacer un 'arreglo'16:

16 "En música, un arreglo es una obra derivada de una obra original". Ver https://es.wikipedia.org/wiki/Arreglo_ (m\%C3\%BAsica).
Yo, intuitivamente, pienso que lo deberíamos proyectar a más de un año (reunión de Junta Directiva: director de la organización, febrero de 2014, transcripción $n^{\circ} .1$, p. 23).

Podrían ser interesante cambiar un poquito la dinámica en cuanto a que sí hubiera, no digo que de planeación estratégica, pero sí algo de..., algo en donde hubiera más construcción colectiva, más que solo decir: "sí" o "no" (...). Si uno mira, en cada junta, en 'varios', hay unos pedacitos súper interesantes y yo creo que podría ser más chévere si se le diera la vuelta a la agenda en ese sentido (entrevista a un miembro de la Junta Directiva, 25 de febrero de 2016, transcripción $\mathrm{n}^{\circ} .12$, p. 4).

En ocasiones, en el curso de las circunstancias, se trató de recurrir también a la 'partitura'17, al plan trazado, aunque, por el protagonismo asignado a las preocupaciones operativas, así como al presente y el pasado, esto no llegó a tener un amplio recibo ni a modificar la dinámica misma de la interpretación. De hecho, esta partitura tenía un carácter altamente confidencial, que impedía que todos los actores concernidos identificaran el plan a seguir:

Hacemos ejercicios de planeación estratégica periódicamente que, en algo, digamos..., ayudan a definir el futuro. Pero creo que tal vez no lo seguimos como muy... o no se hace tan detallado o estrictamente como suele hacerse en otras organizaciones (entrevista al director financiero, 25 de febrero de 2016, transcripción $\mathrm{n}^{\circ} .14$, p. 1).

Estaba pensando que si querían ver el documento de la planeación estratégica. El director del proceso de planeación [miembro de la Junta Directiva] me dijo

17 Una partitura es el "texto de una composición musical correspondiente a cada uno de los instrumentos que la ejecutan". Ver http://dle.rae.es/?w=diccionario. 
que no se podía hacer público, que es confidencial. ¡Entre menos personas lo vean mejor! (reunión de Junta Directiva: director de la organización, febrero de 2014, transcripción $n^{\circ}$. 1, p. 24).

En efecto, en el contexto organizacional estudiado, es clara la existencia de una partitura, de un plan a seguir, que, en realidad, por momentos, quisiera ser retomado por algunos:

La diferencia es notable, supremamente notable y, así como lo vimos en la planeación estratégica, este es el programa al que debemos apuntarle (reunión de Junta Directiva: director de la organización, abril de 2014, transcripción $n^{\circ} .2$, p. 29).

Ese fue uno de los puntos que salió en el planeamiento estratégico. El profesionalizar el tema de la búsqueda de recursos (reunión de Junta Directiva: miembro de la Junta Directiva, septiembre de 2014, transcripción $n^{\circ} .6$, p. 31).

A pesar de esto, asuntos muy concretos presentes en el cotidiano (en la operación), a los que se vio expuesta usualmente la organización, la condujeron a concentrar su atención en acciones improvisadas: simplemente a reaccionar. Esto a pesar de que algunos de ellos hubieran podido ocupar tal vez una menor atención en el día a día, si hubieran sido considerados previamente:

La entidad pública que nos vigila en esta materia me devolvió más o menos diez veces los estatutos (...), porque teníamos que hacer unas modificaciones, más de forma que de fondo. Nos decían: "que en los estatutos nuestros decía la 'corporación' o 'asociación'”. Me dicen: "o son corporación o son asociación” (reunión de Junta Directiva: director de la organización, julio de 2014, transcripción $n^{\circ}$. 4, p. 22).

La parte de la dependencia hacia el Estado [en esta materia] ha sido el mayor problema (reunión de Junta Directiva: miembro de la Junta Directiva, septiembre de 2014, transcripción $n^{\circ}$. 6, p. 37).

Pero leste contrato con una entidad públical fue malo, porque no dio lo que se pensó que iba a dar y demandó mucho más tiempo y mucho más trabajo y no representó lo que... O sea, la plata sí va a entrar, pero no justifica lo que se le invirtió (...) entonces sí fue malo, jlo que terminamos fue en un infierno! (reunión de Junta Directiva: miembro de la Junta Directiva, junio de 2014, transcripción $n^{\circ}$. 3, p. 28).

A pesar de lo anterior, algunos problemas sí fueron identificados con antelación y, de hecho, varios se incorporaron al plan estratégico. Sin embargo, por lo general, era evidente que el camino trazado no era seguido de acuerdo a lo previsto, pues la atención no se ponía en lo estratégico (en el futuro), sino en lo operativo (en el presente y el pasado, en donde el protagonista era el tema financiero):

En el tema del plan de choque, ¿no sería bueno también ver no solo el tema de costos, sino de generar más ingresos? (...) la problemática no es solo porque tengamos más costos (...), sino porque no buscamos diversificar los ingresos (...), que era un poco de lo que hablábamos en el planeamiento estratégico (reunión de Junta Directiva: miembro de la Junta Directiva, julio de 2014, transcripción $n^{\circ} .4$, p. 9).

- Director de la organización: inclusive tenemos unas metas altas y ahora, este mes entrante, vamos a tener que estar haciendo el análisis de cómo vamos con la planeación.

- Miembro de la Junta Directiva: yo pienso que propongan, a veces uno no tiene que hacer o esperar que eso pase (reunión de Junta Directiva: conversación entre miembros de la Junta Directiva, transcripción $n^{\circ} .4$, p. 10). 
De hecho, cuando se trató de volver a la partitura, al plan estratégico formulado, la manera de querer hacerlo daba cuenta de que este, en realidad, no había sido bien considerado y quedaba en evidencia, además, la consideración por parte de algunos directivos de que esto hubiera sido algo valioso. Se presentaba entonces cierta resistencia a la improvisación, un interés de volver a lo prestablecido con el fin de encontrar salidas a la situación organizacional, incluso llegando a considerar que este ejercicio debería ser realizado por terceros:

El año pasado hicimos un esfuerzo grande para hacer la planeación estratégica y antes de ponerse a hacer uno otras cosas más, vale la pena hacer esa sesión que yo he sugerido, de actualización y de saber dónde estamos y dónde están las directrices y dónde se centra el esfuerzo. Y no empezar a desarrollar ideas, cada una por su lado, porque eso termina... (...). Yo creo que se hizo un esfuerzo grande. Se tienen unas bases y es ver qué se ha hecho y qué no se ha hecho, qué sirve, qué se mata de lo que se hizo ahí (reunión de Junta Directiva: miembro de la Junta Directiva, noviembre de 2014, transcripción $n^{\circ}$. 8, p. 28).

Se hizo un planteamiento inicial para estructurar todos los problemas que había, para así poder empezar a evacuar, desarrollando unos lineamientos y algunos planes estratégicos. Y estrategias para eliminar esas barreras (...) salieron cosas interesantes (reunión de Junta Directiva: miembro de la Junta Directiva, noviembre de 2014, transcripción $n^{\circ}$. 8, pp. 29-30).

Yo sí creo que en la planeación sí es muy bueno que venga alguien de afuera y que lo mire a uno y lo escudriñe y le diga: "imire, es por acá!" (entrevista al director de la organización, 4 de marzo de 2016, transcripción $\mathrm{n}^{\circ}$. 11, p. 2).

En las situaciones estudiadas se puso en evidencia, incluso, más que solo una resistencia a la improvi- sación, un cierto temor a la misma. Esto, a pesar de que, como se ha indicado, ella tuvo siempre un elevado protagonismo en la práctica directiva de la organización:

- Miembro de la Junta Directiva: [Reunámonos en el lugar que propongo,] allá tenemos a alguien que hace planeación estratégica y hace los balances y esas cosas.

- Miembro fundador: ¡Ay no! ¡Qué maravilla! Esa reunión me tranquiliza muchísimo, porque me sentía preocupada, [pensaba]: ¡Nos vamos a botar al Salto del Tequendama! [una cascada natural cercana a Bogotá] (reunión de Junta Directiva: conversación entre miembros de la Junta Directiva, noviembre de 2014, transcripción $n^{\circ} .8$, p. 30).

De este modo, a pesar de la existencia de una partitura, de un plan, en la práctica las decisiones se fueron tomando principalmente al filo de las circunstancias y de la interpretación. Estas fueron trazando de manera gradual un determinado patrón que, en el fondo, daba cuenta del interés de lograr un objetivo: la supervivencia de la organización, sin importar las dificultades.

Así, la improvisación fue marcando el ritmo y dando forma, en particular, a una cierta "armonía'18, la

18 En el contexto musical la armonía es "la superposición de sonidos que se producen simultáneamente". Ver https:// oscrove.wordpress.com/teoria-musical/los-elementos-de-lamusica/. Es el "arte de formar y enlazar los acordes". Ver http://dle.rae.es/?w=diccionario.

Con el fin de cuidar aspectos básicos a tener en cuenta al hacer uso de una metáfora (Montoya et al., 2010: 77-80), conviene indicar que, para que exista 'música', deben estar presentes al menos tres de los cuatro elementos citados en esta serie de notas aclaratorias al pie de página, a saber:

Melodía, armonía y ritmo (...), el ruido es carente de armonía, y de melodía (...) en la música existe un orden y disposición de estos elementos (...). El sonido de la repetición de una máquina (...) produce un efecto rítmico similar a un grupo de tambores (...). Una simple observación mostrará que no hay melodía ni armonía, tan solo el ritmo. Y el ritmo es tan solo un elemento de la música, pero no es la música en sí (...) un pájaro canta una melodía, pero tampoco hace música, porque existe una carencia de los demás elementos (el ritmo y la armonía). En otras palabras, podemos entender su sonido como una melodía, pero no es música. (Rothman, 2014: 15) 
cual dio fundamento a la toma de decisiones en función de los diversos problemas que iban emergiendo día a día en la organización:

El año pasado el coordinador financiero nos hacia la sugerencia de que este programa hace un encuentro de egresados (...), nos decía ¿y ustedes por qué no organizan también el encuentro? (reunión de Junta Directiva: invitado a la reunión, abril de 2014, transcripción $n^{\circ} .2$, p. 28).

Tenemos (...) un gran inmueble. Está alquilado (...) a una compañía que los administra, pero (...) han estado incumpliendo (...) les hicimos la concesión de bajarles el arriendo, pero ahoritica nos piden eso otra vez (...), [ya] hablamos con una abogada (reunión de Junta Directiva: director de la organización, junio de 2014, transcripción $n^{\circ} .3$, p. 2).

[Tenemos una casa] muy difícil (...) le tenemos que meter mucha plata para adecuarla y siempre tenemos problemas (...), se nos inunda, tiene problemas en la cocina, en los baños (...). Por más que nosotros le metemos plata, yo siempre veo esa plata como perdida (reunión de Junta Directiva: director de la organización, junio de 2014, transcripción $n^{\circ}$. 3 , p. 26).

¡Yo creo que hay que actuar, algo inmediato! Yo no reemplazaría a las personas que se fueron. Tocaría cubrir los espacios con otras personas, hasta que no tengamos a flote a la organización, racionalizar los gastos, no sé si hay que actuar eventualmente sobre ese programa para bajar los gastos allá también (reunión de Junta Directiva: director financiero, junio de 2014, transcripción $n^{\circ}$. 3, p. 29).

Estos aspectos emergieron usualmente en la interacción entre los individuos, en conversaciones en donde siempre entraba en escena la improvisación:
- Miembro de la Junta Directiva: en la parte digital, pues para dar a conocer la organización, ¿han hecho algo? No sé, pues para difundirla, que la gente conozca qué hace y pues comenzar a mercadear la organización para conseguir recursos.

- Director de la organización: sí, nosotros estamos en las redes sociales y nuestra página no es la mejor, pero sí.

- Miembro de la Junta Directiva: se necesita un ejercicio para mejorar toda esa parte de la página, de redes sociales (reunión de Junta Directiva: conversación entre varios miembros de la Junta Directiva, junio de 2014, transcripción $n^{\circ} .3$, p. 34).

- Miembro fundador: yo tengo una pregunta, ¿no sería bueno patentar el nombre de nuestra organización?

- Miembro de la Junta Directiva: ¿nosotros no estamos en la Superintendencia de Industria y Comercio?

- Director de la organización: nosotros estamos registrados en otra entidad pública.

- Miembro de la Junta Directiva: en la Superintendencia de Industria y Comercio se registran los nombres, lo sé porque yo trabajé allí.

- Presidente de la Junta Directiva: ¡ah! ¡qué bueno! Ya tiene una primera tarea para que nos ayude (reunión de Junta Directiva: conversación entre varios miembros de la Junta Directiva, abril de 2014, transcripción $n^{\circ}$. 2, p. 33).

- Miembro fundador: y quedaría una persona (...) en consecución de recursos. Porque nos damos cuenta, hay que conseguir plata, pero ¿cómo la vamos a conseguir?

- Miembro de la Junta Directiva: es que no es fácil. 
- Presidente de la Junta Directiva: es el mensaje permanente: "ihay que conseguir la plata!", pero no se concreta. ¡Hay que estructurarlo! (reunión de Junta Directiva: conversación entre varios miembros de la Junta Directiva, diciembre de 2014, transcripción $n^{\circ} .9$, p. 11).

La improvisación emergía en la medida en que la organización, en el cotidiano, debía enfrentar asuntos relevantes. Estuvo entonces en la base de las decisiones tomadas por los directivos, fue la melodía principalmente escuchada en cada reunión:

Estoy tratando de dar una solución, iafrontemos el problema! (...) tengamos la licencia para la licitación (...), ya después de eso volvemos a la situación anterior y vemos cómo lo solucionamos (reunión de Junta Directiva: miembro de la Junta Directiva, agosto de 2014, transcripción $n^{\circ} .5$, pp. 24-25).

Interesante mirar cómo podemos ampliar la capacidad de dos de las sedes para absorber a los usuarios de la otra, así nos queda una libre (reunión de Junta Directiva: director financiero, octubre de 2014, transcripción $n^{\circ} .7$, p. 18).

[Dado que hay que aplicar las Normas Internacionales de la Información Financiera NIIF] pues háganos una propuesta [indicación al contador] y qué decimos y eso. $Y($...) usted diga: "ilas políticas son estas!” (...) decimos: “ok” (...) y jestamos listos! ¡No hay que ponerle mucha ciencia al tema! (reunión de Junta Directiva: director financiero, octubre de 2014, transcripción $n^{\circ} .7$, p. 18).

Teniendo en cuenta esos aspectos me reuní con un amigo que tiene una empresa de consultoría (...) basada en el modelo de Google. La idea es organizarnos con él para que nos envíe una propuesta de una asesoría sobre qué es lo que debemos hacer (reunión de Junta Directiva: coordinador financiero, noviembre de 2014, transcripción $n^{\circ} .8$, p. 26).

Necesitamos encontrar esa plata permanentemente, ilo de las becas se me ocurrió ahoritica! (reunión de Junta Directiva: miembro fundador, diciembre de 2014, transcripción $\mathrm{n}^{\circ} .9$, p. 11).

Los requerimientos del ente contratante (...) no nos permiten planear, sino dar respuesta a lo que ellos están exigiendo (...) ahí es una cosa más reactiva que de planeación (entrevista al director de la organización, 4 de marzo de 2016, transcripción $\mathrm{n}^{\circ} .11$, p. 1).

Así, múltiples ideas emergen en los diferentes espacios directivos con el fin de conseguir recursos y de hacer viable a la organización. De algún modo, se actúa en función de las circunstancias y, luego, retrospectivamente, se reconstruye y justifica la historia previamente realizada:

Intentamos hacer las cosas bien y eso nos acarreó problemas. Sin embargo (...), el contrato ya finalizó, los problemas que hay que subsanar son mínimos y pudimos llevar el contrato de una manera honesta y correcta. No sabemos si nos vaya a dejar utilidad (reunión de Junta Directiva: coordinador financiero, septiembre de 2014, transcripción $n^{\circ} .6$, p. 11).

Vale la pena ese informe (...), financieramente con lo que implicó y terminó no siendo bueno, pero también, socialmente, qué se hizo (...) tener ese pequeño informe de qué fue y qué pasó. De todas maneras, se le metió mucho trabajo, mucho esfuerzo (...) tener una memoria chiquita de qué fue lo que pasó (reunión de Junta Directiva: miembro de la Junta Directiva, septiembre de 2014, transcripción $n^{\circ} .6$, p. 12).

En efecto, aunque en la práctica se configure gradualmente un patrón al interior de una serie de de- 
cisiones tomadas por los directivos - o una estrategia emergente-, punto a punto, en función de la improvisación, algunos actores tratan de construir argumentos más formales y atribuir un peso a lo prestablecido (a la partitura). Esto, tal vez, como una forma de justificar el ejercicio y de defender la existencia de una lógica predeterminada en lo realizado:

[En nuestra organización], jclaro que hay [planeación]! (...) se hace cada dos años (...). Sí, por lo menos se logra como una claridad general de todos, de para dónde vamos, después de compartir distintos ejercicios, idefinitivamente sí! (entrevista a un miembro de la Junta Directiva, 25 de febrero de 2016, transcripción $n^{\circ}$. 12, p. 1).

Ahora bien, la mayoría de actores que dieron forma a las situaciones estudiadas tienen representaciones distintas respecto a estos espacios directivos. Sin embargo, son conscientes de que lo operativo y, en particular, lo financiero ${ }^{19}$, así como la consideración de los asuntos presentes y pasados, son temas preponderantes:

La Junta de la organización tiende a volverse muy operativa (...). Buena parte de su foco de Junta es la parte financiera y ila parte financiera parece como si fuera el rey! (entrevista a un miembro de la Junta Directiva, 22 de febrero de 2016, transcripción $\mathrm{n}^{\circ}$. 13, p. 4).

Vamos a la Junta es a que nos cuenten cómo ha sido el mes, qué ha pasado en los diferentes programas (...). Me da la impresión de que vamos es a que nos cuenten cómo está la situación (entrevista al director financiero, 25 de febrero de 2016, transcripción $n^{\circ}$. 14, p. 1).

19 Esto sin que, en realidad, la totalidad de los presentes en las juntas directivas conozcan bien estos asuntos. Lo anterior implica, entonces, confianza en lo que los demás dicen a la hora de tomar decisiones.
[Se] tienen unas angustias que hacen que la junta pierda a veces un poquito su foco de planeación estratégica y esté más centrada en la planeación del día a día (entrevista a un miembro de la Junta Directiva, 22 de febrero de 2016, transcripción $\mathrm{n}^{\circ} .13$, p. 1).

La parte financiera lo embiste a uno un poco, porque uno no entiende lo que se está presentando (...). Alguna vez en una junta (...) el director financiero dijo: “ise aprueban?" y uno mira y dice: "pues, en cuanto le creo que lo que está diciendo usted es sensato, porque yo entender a profundidad qué está pasando, ¡pues no!" (entrevista a un miembro de la Junta Directiva, 25 de febrero de 2016, transcripción $n^{\circ} .12$, p. 4).

Me da la impresión muchas veces que en la reunión de Junta no hay claridad hacia dónde está el futuro (entrevista a un miembro de la Junta Directiva, 9 de marzo de 2016, transcripción $n^{\circ}$. 10, p. 3).

[Está] lo de la parte estratégica, que es a lo que nunca le dedicamos tiempo (entrevista a un miembro de la Junta Directiva, 9 de marzo de 2016, transcripción $n^{\circ}$. 10, p. 4)

Desde lo financiero estamos muy restringidos (...), ahora lo que queremos es conseguir platica (...). No me gustó esa planeación estratégica. Yo siento que (...) estaba mucho más dirigida a conseguir plata (...). Yo quería que (...) me dijeran hacia dónde íbamos a ir (entrevista al director de la organización, 4 de marzo de 2016, transcripción $n^{\circ} .11$, p. 1).

Yo creo que se tiene una Junta que planea, pero planea más, digamos, con base en las restricciones, más que en las posibilidades. Es lo que yo percibo (entrevista a un miembro de la Junta Directiva, 22 de febrero de 2016, transcripción $\mathrm{n}^{\circ} .13$, p. 1). 


\section{Discusión}

El análisis del material empírico recabado a partir de las situaciones estudiadas (considerando los actos, los agentes, la escena, los propósitos y las acciones en sí), así como de la propia representación de los actores en relación con las mismas, los documentos, las notas y los conceptos de diversos expertos (del mundo empresarial y el musical), permitió identificar varios aspectos que se consideran a continuación sobre la base de lo presentado en el apartado anterior:

\subsection{La estrategia emergente sigue a la delibera- da... como el pie izquierdo al derecho}

Existen múltiples representaciones acerca del concepto de 'estrategia' (Mintzberg, 1987b). Entre ellas, por su carácter aparentemente opuesto, se destacan dos: 1) la que plantea que esta corresponde a un 'diseño' (Mintzberg, 1990a) y 2) la que propone que es más bien un 'patrón' determinado al interior de una serie de acciones (Mintzberg \& Waters, 1985: 257). En la primera opción lo prestablecido es esencial, la existencia de un libreto a seguir, de una partitura o de un plan deliberadamente pensado y seguido de manera rigurosa, guiado por un director, hasta alcanzar los objetivos trazados. En la segunda, lo emergente es central, así como la capacidad de improvisación que los actores consiguen lograr al enfrentar las circunstancias que viven en el presente, mientras avanzan hacia el futuro.

Esta aparente dicotomía, se disuelve, de algún modo, en el contexto de esta investigación. Esto de acuerdo con los resultados encontrados. Tal como indica uno de los participantes:

¿Planeación estratégica o improvisación estratégica? Yo creo que todos los extremos son viciosos, ¿no? Ni es bueno tener una estrategia de tal manera que se vuelva rígida y entonces se llega al extremo de decir: "es que no podemos hacer nada, porque la estrategia dice esto y no hay ninguna posibilidad de cambio". No creo que eso sea bueno. Ni tampoco que sea bueno el extremo de decir: "yo no planeo y simplemente veo la oportunidad" (entrevista a un miembro de la Junta Directiva, 9 de marzo de 2016, transcripción $n^{\circ}$. 10, p. 1).

Así, en línea con lo que trabajos anteriores han identificado (Hernández et al., 2015; Mintzberg, 1987a; Montoya, 2010), se encuentra que la estrategia deliberada y la emergente no son, por obligación, alternativas mutuamente excluyentes. En realidad, ambas coexisten en el contexto organizacional, aunque con diferentes grados de intensidad en función de las circunstancias. En efecto, en la organización estudiada es evidente la existencia de planes formales, pero también la prevalencia de una serie de decisiones que van configurando un patrón en una corriente de posibles opciones (Mintzberg, 1978), un espacio en el que la improvisación ocupa un lugar esencial.

De hecho, la improvisación como fenómeno, no solo en el mundo de la música (Vera \& Crossan, 2004), encuentra cabida, tal vez, como lo hizo en el campo de la estrategia, en el marco de las tensiones (Schvarstein, 2000) existentes entre tradición y renovación (Aktouf, 2001), orden y desorden (Morin, 1981), invariancia y cambio (Etkin \& Schvarstein, 2000) y lo deliberado y lo emergente (Mintzberg \& Waters, 1985).

Así, en el proceso de evolución del discurso estratégico, frente al aparente desorden teórico existente antes de su conformación, algunos actores propusieron ideas con el fin de estabilizar las cosas de algún modo y proveer una lógica y un sentido particulares al campo (Ackoff, 1970; Andrews, 1971/1980; Ansoff, 1965; Ansoff \& Hayes, 1976; Chandler, 1962/1990; Hofer \& Schendel, 1978; Learned et al., 1965/1969). Luego, en el desarrollo de las tensiones indicadas en el párrafo anterior, surgieron otros que, tal vez con cierta rebeldía ante el statu quo constituido por los primeros, consideraron que tal ordenamiento no correspondía con la realidad propia de la naturaleza humana y que era, de algún modo, artificial. Estos plantearon entonces esquemas que dieron una mayor cabida a aspectos como la incertidumbre, el error, la adaptabilidad, la creatividad y la propia improvisación (Mintzberg, 1971, 
1973, 1975, 1976, 1977, 1978, 1981, 1987a, 1987b; Mintzberg \& Waters, 1985; Patrick, 2008; Quinn, 1978, 1980; Teoh \& Wickramasinghe, 2012). De hecho, un proceso similar es también visible en relación con el lugar que ocupa esta última variable en el contexto musical:

En la música popular siempre ha existido la improvisación y nunca se ha dejado de hacer. Pero en la música académica o erudita, sí hubo un momento en que los músicos que escribían dijeron: "ino!, no vamos a dejar a la deriva nada, vamos a escribir, si el músico va a tener un solo, lo vamos a escribir". Entonces en ese momento se dejaron de hacer improvisaciones espontáneas (entrevista a un músico guitarrista experimentado, 6 de marzo de 2016, transcripción $n^{\circ}$. 18, pp. 2-3).

Lo único que, digamos, no es improvisación, es la música clásica. Aunque Bach era uno de los más grandes improvisadores (...). Toda la música popular está basada en improvisación (...). El jazz también lo tiene. El papel de la improvisación en el jazz es todo. (...). Entonces la improvisación lo es todo. Los grandes jazzistas son los grandes improvisadores (entrevista a un músico guitarrista experimentado, 10 de Marzo de 2016, transcripción $n^{\circ} .16$, p. 2).

De este modo, tal como Mintzberg (1990a) encontró que "la estructura sigue a la estrategia... como el pie izquierdo sigue al derecho" (p. 183), es posible indicar también aquí, a partir de lo identificado en esta investigación, que es posible encontrar una relación similar, aunque con dos conceptos distintos. Así, de acuerdo con nuestros resultados: "la estrategia emergente sigue a la deliberada... como el pie izquierdo sigue al derecho" y, además, se encuentra que un aspecto inevitable en el juego entre una y otra, en contexto de esta relación, es la improvisación.

\subsection{No solo la muerte y los impuestos son inevi- tables: también lo es la improvisación}

En una célebre carta deBenjamin Franklin a JeanBaptiste Leroy (en 1789) este indicó: "Nuestra nueva constitución está ahora establecida, y tiene una apariencia que promete permanencia; pero en este mundo nada puede ser dado como cierto, excepto la muerte y los impuestos" ${ }^{20}$. En el contexto organizacional estudiado, de acuerdo con los resultados de esta investigación, es evidente que al final de esta sentencia podrían ser agregadas tres palabras más: "y la improvisación". Esta, en efecto, se encuentra por doquier en el contexto organizacional estudiado y, de acuerdo con lo encontrado, es ciertamente inevitable. Esto, entre otras razones, dada la incertidumbre que caracteriza nuestras decisiones (Soto et al., 2005) y la racionalidad limitada que las sustenta (Simon, 1979, 1982). Estos aspectos, de hecho, están en la base de la argumentación de Mintzberg y Waters (1985) acerca de la imposibilidad de encontrar en la práctica, en el mundo real, estrategias deliberadas o emergentes puras.

Un actor protagónico de las situaciones estudiadas, en concordancia con esto, afirmó lo siguiente:

Yo creo que las oportunidades aparecen y uno no las puede desaprovechar. Creo que esa parte de improvisación es necesaria, iporque así es la vida misma! (entrevista a un miembro de la Junta Directiva, 9 de marzo de 2016, transcripción $n^{\circ}$. 10, p. 2).

En esto, de hecho, el anterior entrevistado coincide con el criterio de uno de los músicos expertos consultados:

Improvisar tiene que ver con el proceso de creación del ser humano (entrevista a un músico guitarrista experimentado, 6 de marzo de 2016, transcripción $n^{\circ} .18$, p. 1)

20 Ver https://en.wikipedia.org/wiki/Death_and_taxes_(idiom). 
Así, las estrategias emergentes se soportan, en lo fundamental, de acuerdo con los resultados de esta investigación, en la improvisación. A esta se ven enfrentadas las organizaciones dada la necesidad de lidiar con acciones, decisiones y fenómenos que están por fuera de su control. De hecho, nadie, por poderoso que sea, tiene el completo control de todo en este mundo. Esta imposibilidad lógica conduce entonces a la necesidad de improvisar. De este modo, en las organizaciones, como en la vida misma, tal como indicó Antonio Machado: "se hace camino al andar", y la herramienta con la que se va abriendo dicho camino es la improvisación.

Ahora bien, incluso en el contexto de la formulación de estrategias deliberadas, así como en la composición musical que deriva en una partitura, la improvisación tiene cabida. Esto no solo por los argumentos arriba expuestos (ver sección 2.4.) -a pesar de no existir un consenso al respecto (ver tabla 3)- y por lo que se acaba de indicar, sino también porque la concepción de una estrategia implica un proceso de creación (Mintzberg, 2007), así como la identificación y generación de alternativas en función de circunstancias muy particulares y, en esa medida, implica igualmente la necesidad de improvisar.

En este sentido, incluso, es posible llegar a considerar en la práctica exitosa de los negocios, posiciones extremas en relación con la importancia de la improvisación, tales como la de Jean Claude Bessudo (2007), Presidente del Grupo Aviatur en Colombia. Él indica lo siguiente:

Mi concepto es que jla planeación estratégica está al alcance de cualquier retardado mental! ¡Punto! Es apenas lógica..., la lógica: iprimero usted construye el piso y luego el techo y no la casa! (...). Hoy en día llaman a eso gerencia por escenarios: usted pruebe cincuenta escenarios, iDios lo bendiga!, $y$, ipreciso le toca el cincuenta y uno! Y las empresas que sobreviven no son las más inteligentes, no son las que más planifican, no son las más grandes; las que sobreviven son las que mejor se adaptan. [Mi perspectiva al respecto, de cualquier manera,] no subestima a la planeación [simplemente indica], lo que dije, [que] está al alcance de cualquier retardado que haga su trabajo (entrevista al empresario Jean Claude Bessudo, 23 de febrero de 2016, transcripción $\mathrm{n}^{\circ} .15$, p. 1)

¡Actuemos sobre lo que está ocurriendo! Yo no pierdo mi tiempo en (...) hacer programas a cinco años. ¡Si eso no depende de mí! (entrevista al empresario Jean Claude Bessudo, 23 de febrero de 2016, transcripción $n^{\circ} .15$, p. 1).

Todo surge al final (...). Para poder improvisar (...) la meta es que la empresa sobreviva. iHágalo lo mejor posible y punto! Lo que usted esperaba cambió en un segundo, jadáptese! (...), jhagámoslo! La imaginación es tu único límite (entrevista al empresario Jean Claude Bessudo, 23 de febrero de 2016, transcripción $n^{\circ}$. 15 , pp. 3-5).

La mía es una forma de trabajar y punto. No hay fórmula mágica (entrevista al empresario Jean Claude Bessudo, 23 de febrero de 2016, transcripción $n^{\circ}$. 15, p. 7).

En lo anterior, a pesar de su radicalidad, este empresario coincide con representaciones que parecen más naturales y fáciles de aceptar en el mundo de la música, que en el de las organizaciones:

Para mí la improvisación lo es todo. Y esto representa a veces discusiones, porque hay personas que están acostumbradas a hacer todo conforme a un orden. Pero la vida es eso, la vida es obstáculos todos los días, la vida es que yo quería llegar a las dos, pero hay trancón, entonces ¿qué voy a hacer? El jazz es la vida y la improvisación es la vida. Todo lo que uno debe hacer. Las personas que no improvisan en la vida sufren mucho. Porque las cosas no ocurren como uno quiere y esa es la vida, el mundo es difícil de sobrellevar (...). ¡La vida es 
la improvisación! (entrevista a un músico guitarrista experimentado, 10 de marzo de 2016, transcripción $n^{\circ} .16$, p. 3).

La improvisación es súper importante en la música. Porque es la capacidad de resolver en algún momento en el que toca hacerlo. Es decir, ya está allá parado y hay que tocar, ipues toque! (entrevista a un músico bajista experimentado, 4 de marzo de 2016, transcripción $n^{\circ} .17$, p. 1)

La improvisación, de acuerdo con nuestro trabajo, está presente entonces en todo momento de la vida de la organización estudiada, tanto en la concepción de estrategias deliberadas como en la formación de estrategias emergentes. De hecho, tiene que ver, de manera más profunda, en lo fundamental, con la propia naturaleza incierta, evolutiva y adaptativa de la existencia humana y su lucha por sobrevivir. Esto es más fácil de aceptar, en particular, cuando se considera que la estrategia se trata de ser úni$\mathrm{co}$, que esta es la fuente de una ventaja competitiva verdaderamente sostenible, pues, según autores destacados en el campo, como Porter (1996), no hay otra forma de alcanzar algo así, sino a partir de distinguirse a través de aquellos factores que no son fácilmente imitables:

Entonces digamos que la improvisación es una necesidad de búsqueda (entrevista a un músico guitarrista experimentado, 6 de marzo de 2016, transcripción $n^{\circ} .18$, p. 3).

Valdría la pena terminar este apartado indicando algo que fue notable a lo largo de las sesiones estudiadas y que es parte central del discurso del experto empresarial consultado (J.-C. Bessudo): la improvisación está presente de manera constante en el actuar de la organización, pero improvisar requiere ciertos parámetros, uno de ellos, que es fundamental, es el actuar correcto:

¡Mucha ética! No apartarse de ella, por más que las tentaciones sean enormes, imucha ética! (entrevista al empresario Jean Claude Bessudo, 23 de febrero de 2016, transcripción $n^{\circ} .15$, p. 7).
Así, a partir de lo incorporado en este apartado, se identifica que aunque la improvisación está tanto en lo deliberado como en lo emergente, existe una intensidad mayor de su presencia en lo segundo que en lo primero. Además, una serie de consideraciones adicionales emergen de esto: la existencia de múltiples factores complementarios y de parámetros que, como el que acabamos de mencionar, son esenciales para su realización en el contexto administrativo. A estos aspectos se dedica el siguiente apartado.

\subsection{La improvisación no está tanto en el 'qué' sino en el 'cómo', aunque ambos aspectos se complementan}

Un elemento central del direccionamiento estratégico es la definición de fines y medios, de metas y métodos o, en otras palabras, de determinados 'qué' y 'cómo' (Falconi, 1996). Aunque, como se indicó en la sección anterior, la improvisación está por doquier en el contexto organizacional y su presencia en la estrategia se muestra como algo inevitable; parece también, a partir de los resultados de nuestra investigación, que existe una mayor intensidad de su presencia en el 'cómo' que en el 'qué. En efecto, algunos de los actores estudiados soportan esta consideración de la siguiente manera:

Creo que hay que creer en la planeación, pero creo que no puede ser uno tan estricto que se tiene que limitar a la gente a las directrices que le genera la planeación. Tiene que tener esa apertura de mente, para ir asimilando lo que se le va presentando en el día a día en el que uno se ha fijado como un norte (...), uno debe tratar de fijar su norte para no perderlo, pero tiene que tener la capacidad de irse adaptando a las circunstancias en un mundo tan cambiante como es este (...). Pero ya... ¿cómo llegar al norte? Puede haber muchos caminos (entrevista a un miembro de la Junta Directiva, 22 de febrero de 2016, transcripción $n^{\circ}$. 13, p. 2).

Se trata de tener un faro. Alguien me decía: "apunte a las estrellas para llegar 
a la luna”. [La] improvisación no es mala (...) es entender que el mundo no es tan rígido (...). Quizás en el punto medio está la solución (entrevista a un miembro de la Junta Directiva, 9 de marzo de 2016, transcripción $\mathrm{n}^{\circ}$. 10, p. 4).

Siempre se hace un presupuesto anual (...). Sin embargo (...), es muy difícil que uno le atine a los presupuestos (...). Siempre se está improvisando y realmente es muy complicado a veces (entrevista al director financiero, 25 de febrero de 2016, transcripción $n^{\circ}$. 14, p. 1).

Así, de acuerdo con lo encontrado, aunque la improvisación tiene lugar tanto en el momento de la formulación de la estrategia como en su implementación, parece más evidente, atendiendo a la intensidad de su presencia, que esta es mucho más sonora en la segunda actividad que en la primera. De este modo, el norte hacia el que se pretende avanzar (el 'qué') provee la dirección, la cual puede llegar a mantenerse - de acuerdo con el criterio de la organización y la dinámica del medio- relativamente estable. Sin embargo, usualmente es en el despliegue de la estrategia y en su ejecución (el 'cómo') en donde, en lo fundamental, se hace presente la improvisación. Esto debido al surgimiento de una serie de elementos emergentes e impredecibles. Puede decirse entonces que se fija el 'qué', de manera más bien deliberada, y se improvisa principalmente en el 'cómo'. Ésta, al parecer, resulta ser la configuración más usual, a partir de nuestros resultados.

Esto coincide de algún modo con lo aprendido gracias al acercamiento al mundo de la música, en donde, a pesar de identificarse múltiples perspectivas al respecto (ver sección 2.4.), se encuentra que, por lo general, no todo es azar. Existen también múltiples aspectos que los músicos deben conocer, una disposición y una autonomía en los mismos, una destacada capacidad para improvisar, unos acuerdos mínimos $y$, como es frecuente encontrar, incluso, una partitura.

De algún modo, la improvisación puede ser entendida entonces como una capacidad dinámica de la organización (Helfat et al., 2007; Teece, Pisano, \& Shuen, 1997), la cual es necesaria para enfrentar las cambiantes situaciones cotidianas que emergen en el medio interno y externo. Ésta la habilita para surfear la creciente complejidad del mismo (Pascale, 1999; Pascale, Millemann, \& Gioja, 2000). Ella, de hecho, puede llegar a ser - dado el lugar identificado en este trabajo para la misma, en la formación de estrategias emergentes - una fuente de ventaja competitiva sostenible. Esto dado que, entre otras características (como su realización in situ y su reciclaje constante), es difícilmente imitable (Barney, 1997; Montgomery \& Porter, 1991; Porter, 1985, 1987).

La improvisación, sin embargo, salvo en casos relativamente extraños, aún en la actualidad, como el de empresarios tales como Bessudo (2007), no es un proceso del que el común de los directivos se sienta orgulloso y del cual, por ejemplo, llegue a presumir. Como fue posible identificar en las situaciones estudiadas, en contraste con las entrevistas realizadas a los actores concernidos, los individuos, más que seguir un proceso previamente establecido, dando forma a una estrategia deliberada, improvisan en el cotidiano, dando vida, a través de esto, a estrategias emergentes. Ahora bien, después, de manera retrospectiva, construyen un sentido acerca de lo sucedido.

Esto corresponde entonces con un proceso característico de sensemaking (Weick, 1995, 2001, 2009), en el cual se desarrollan argumentos con el fin de justificar lo que ya se ha hecho, en algunos, casos atando los hilos necesarios, por ejemplo, a lo indicado en el plan estratégico y, en otros, construyendo argumentos expost para 'evidenciar' la lógica y la coherencia de lo realizado. Se siente entonces una presión, que no necesariamente tienen personajes como Bessudo (2007), de mostrar que lo que se hace está bien fundamentado y ha sido bien pensado y, por lo general, se encuentran los argumentos necesarios para hacerlo. Esto confirma el carácter longitudinal de las estrategias emergentes $y$, refuerza en las mismas su tono retrospectivo. Como indica uno de los participantes:

Las cosas tan planeadas a mí, personalmente, no me hacen muy feliz. De 
hecho, cuando trabajé como profesor en un colegio, yo el viernes por la tarde llenaba el planeador de la semana que ya había hecho. Por decir qué se había hecho (...). Yo creo que ese es uno de los éxitos de nuestra organización (...). En la parte técnica, definitivamente se hace eso todo el día (entrevista a un miembro de la Junta Directiva, 25 de febrero de 2016, transcripción $n^{\circ}$. 12, pp. 2-3).

Lo identificado aquí, entonces, soporta la idea, relativamente reciente en el campo, de que la estrategia, como una obra musical libre (p. ej., en el free jazz) simplemente 'se realiza', de que es, en esencia, 'una práctica' (Golsorkhi, Rouleau, Seidl, \& Vaara, 2010b; Jarzabkowski, 2005). La estrategia no aparece en el contexto de este estudio, en efecto, como algo que la organización necesariamente 'tiene', sino como algo que ella 'hace' (Golsorkhi, Rouleau, Seidl, \& Vaara, 2010a) y que, en consecuencia, es, en la base, un asunto idiosincrático (Whittington, 1996). Así, es necesario considerar tanto la formulación como la formación y la implementación de la estrategia, pero en la medida en la que estas se ven materializadas en el día a día o, en otras palabras, en la microestrategia (Johnson, Melin, \& Whittington, 2003).

Esta mirada, centrada principalmente en "quiénes son los estrategas (administradores, asesores, analistas), qué hacen estos estrategas (planear, revisar, cubrir, hablar y así), y la manera en que las actividades estratégicas devienen socialmente realizadas (legitimidad, presencia, autoridad)" (Chia \& Holt, 2009: 120), en línea con lo abordado en esta investigación, conduce a considerar aspectos como la improvisación, en función de la formación de las estrategias, pero también en relación con otra serie de variables que valdría la pena considerar.

De este modo, de acuerdo a lo indicado por uno de los participantes en la investigación, un aspecto a tener en cuenta a la hora de evaluar la presencia y la intensidad de la improvisación, entre otros posibles, es el tamaño de la organización:

La gran diferencia entre una empresa grande y una pequeña, es el grado de improvisación (...). Ninguna empresa mediana o pequeña llegará a ser grande si no aprende que la formalización, la estandarización, los controles y el método son obligatorios para poder crecer (...). Posiblemente, la gran diferencia entre una empresa grande y una pequeña está ahí. Creo que en las empresas pequeñas se improvisa mucho. En una empresa pequeña está el dueño que hace de todo. Entonces, gran parte del diario se le va en actividades que no puede delegar (...) siempre está improvisando, porque no tiene tiempo de planear. Y puede ser un tipo muy creativo y tener muy buenas ideas. Y a medida que crece, le toca formalizarse para poder crecer $y$, al hacerse mediano, ya no puede hacerlo todo, tiene que aprender a delegar (...). Creo que la improvisación es para las empresas pequeñas y que esta va despareciendo, un poco, a medida que estas crecen. ¡Yo no me imagino a General Motors improvisando! (entrevista a un miembro de la Junta Directiva, 9 de marzo de 2016, transcripción $n^{\circ} .10$, p. 6).

Esto, por cierto, coincide de manera casi exacta con lo identificado por uno de los músicos expertos consultados para esta investigación, en relación con lo que sucede en su propio campo:

Hay que mirar un poco el papel del director en la historia (...) el director aparece cuando las bandas empiezan a crecer. Antes no había directores. Simplemente los músicos se miraban y arrancaban. Siempre fue así y llegó un momento en que fue difícil que todos se miraran, porque eran muchos, por ejemplo en los coros. Miremos el canto gregoriano: se necesitó un director porque había mucha gente y había alguien que tenía que llevar el tiempo, porque si no, se volvía la locura. Entonces digamos que el director nace ya por la necesidad de poder dirigir o conducir. Incluso el nombre en español es dirigir, pero en inglés es "conducting", 
para decir que quien lo hace es el que conduce (...). El director nace cuando ya no podemos mirarnos. Cuando hay cuartetos pequeños o tríos no se requiere un director, sino que todos los músicos prácticamente se van dirigiendo entre sí, porque no se necesita (entrevista a un músico guitarrista experimentado, 6 de marzo de 2016, transcripción $n^{\circ}$. 18, pp. 3-4).

En este punto, valdría la pena reflexionar, en particular, acerca de una de las ideas expresadas por este último participante, a saber: "el director nace cuando ya no podemos mirarnos". Así, en el contexto musical, como en el organizacional y estratégico, tal vez en la medida en la que las organizaciones incrementan su complejidad (Pina e Cunha \& Vieira da Cunha, 2012), entre otras características, por la presencia de un mayor número de individuos y por la naturaleza de los mismos (Genelot, 2001), emerge con más fuerza la figura del director y se ve restringido, por esta situación, la presencia de procesos complejos responsivos - o sensibles- de interrelación humana (Stacey, 2001, 2011, 2012). De este modo, en la medida en que los individuos no pueden interactuar de manera directa, informándose in vivo de las acciones de los otros, para poder improvisar conjuntamente, se reduce la intensidad de esta actividad, mientras se incrementa la que caracteriza a la formalización.

Puede que las organizaciones, cuando son nacientes y no han alcanzado un gran tamaño, por ejemplo, tiendan a improvisar en sus diversas áreas, funcionales y directivas y a ver esta actividad como algo más natural en su contexto organizativo. Sin embargo, a medida que van creciendo y madurando, comiencen a identificarla con el desorden, con la falta de preparación y, en consecuencia, con el ruido. Al igual que sucede en géneros como el jazz, entonces, podría llegar a considerarse que la improvisación en las organizaciones tiene un cierto limite, que se impone en función de variables como el tamaño, la trayectoria y el nivel de complejidad de la organización. Cuando este límite, que es distinto en cada organización, es sobrepasado, la improvisación puede llegar a ser entendida como un ruido, como algo sin sentido.
Una variable adicional que puede ser relevante en este fenómeno, entre otras posibles, es también el sector de actividad en el que se encuentre la organización y la dinámica que lo caracteriza. Así, en determinados contextos industriales, por ejemplo, tipificados por cierta estabilidad, la improvisación puede perder intensidad, mientras la formalización puede ganarla. En cambio, en otros más dinámicos, como en el de los servicios, la tendencia puede ser la inversa:

Yo no estaría de acuerdo con eso [de la improvisación] en las organizaciones en las que yo soy miembro de Junta. A nosotros nos toca hacer inversiones muy grandes en maquinaria para la parte de empresas de fabricación, donde uno tiene que ver, con un año de anticipación, qué es lo que se demora en hacer la máquina y ver que vamos a tener un aumento en la demanda y cómo vamos a hacer para pagar esa máquina (entrevista al director financiero, 25 de febrero de 2016, transcripción $n^{\circ} .14$, p. 3).

La dinámica del sector, como una característica esencial de la estrategia, es un asunto central, entonces no solo para discursos como el de las capacidades dinámicas (Eisenhardt \& Martin, 2000; Teece et al., 1997; Wang \& Ahmed, 2007), sino también, en consonancia con esta línea, para la comprensión de las estrategias emergentes en las organizaciones $y$ del rol que en ellas ocupa la improvisación. La dinámica mencionada, de algún modo, marca el 'tempo'21 de la organización y, en consecuencia, de la improvisación y de la dificultad que ella implica.

Así, retomando lo indicado al inicio de este apartado $y$, avanzando sobre ello, es posible indicar que para improvisar de manera adecuada conviene contar al menos con dos elementos, además de los otros aquí ya indicados. Estos son: 1) un norte (ubicado después, en el futuro, a la manera de guía y

21 El "tempo (en plural, tempi), movimiento o aire en terminología musical hacen referencia a la velocidad con la que debe ejecutarse una pieza musical". Ver https://es.wikipedia.org/ wiki/Tempo. 
punto de referencia, para guiar - no determinarla acción) y, con base en lo identificado tanto en la organización estudiada, como gracias a la metáfora musical utilizada, 2) una adecuada preparación (antes), así como creatividad, adaptabilidad, flexibilidad y voluntad (durante).

Aunque en ambos puntos está presente la improvisación, se encuentra en este trabajo que, en esencia, se predetermina y prestablece principalmente el 'qué', el norte, mientras se improvisa esencialmente en el 'cómo', es decir, en la trayectoria construida para tratar de llegar a él. Se trata entonces, de algún modo, de hacer una interpretación, para la cual, sin saber qué pueda pasar en el escenario, siempre hay que estar preparado. Esto, aunque no garantiza el éxito, incrementa las probabilidades de llegar a realizar bien esa actividad.

\subsection{Improvisación implica preparación, tanto en el mundo musical como en el organizacional}

La improvisación cumple un papel destacado que aporta, en gran medida, a la formación de estrategias tanto deliberadas como emergentes y, por esta vía, así como por su potencial aporte a la capacidad de adaptación, a la supervivencia y la perdurabilidad de una organización como la estudiada (De Geus, 1997; Riviezzo, Skippari, \& Garofano, 2015). De acuerdo con lo identificado, a partir del trabajo realizado, parecería que para poder improvisar de una manera efectiva se requiere la existencia de una partitura, de una determinada planeación, pero también de la apertura necesaria para adaptarse a las eventualidades que emergen durante la implementación. De acuerdo con lo observado en nuestra investigación, esto es válido, de diversas formas, tanto en el contexto musical (p. ej., en el jazz) como en el organizacional.

A partir del trabajo realizado se pudo identificar, como se observa en la sección de resultados, que en las estrategias emergentes en las organizaciones, de manera análoga a lo que sucede en el jazz, por ejemplo, se requiere el desarrollo de las habilidades necesarias para poder realizar una adecuada improvisación. De esto da cuenta uno de los actores protagónicos de las situaciones estudiadas:
Aunque se haya hecho improvisación, que sí hay, y, en muchas cosas nosotros hemos improvisado, pero, cuando se han tomado decisiones, no se han tomado inconscientemente (...). Nuestras decisiones siempre han sido el fruto de una reflexión (...). Entonces, como digo, son conocimientos que uno ya tiene y yo propongo allá: "mire, trabajemos esto y lo que se está haciendo es esto" (...). Claro, ino es una cosa a la loca! iNo puede ser una cosa a la loca! (...). No sé cuál es la diferencia entre la improvisación y la planeación, a decir verdad, muchas veces uno no puede cumplir con lo planeado, porque la circunstancia es distinta. Uno puede pensar, desde lo ideal, que todo va a ser así como alineadito, pero la realidad no es esa (entrevista al director de la organización, 4 de marzo de 2016, transcripción $n^{\circ}$. 11, pp. 3-4).

Esto coincide, de hecho, con lo indicado por los diferentes músicos expertos consultados en el marco de nuestra investigación:

La improvisación no es completamente improvisación. O sea, la improvisación es el resultado de una cantidad de ejercicios, de una cantidad de escalas, de una cantidad de música que yo he venido escuchando durante mucho tiempo $y$ cómo en algún momento yo la puedo aplicar. No de la misma forma como estaría hecha, sino de una forma personal. Muchas veces uno se aprende frases, se aprende melodías, se aprende escalas, pero no caben en todas las partes de la improvisación (...). Entonces es lograr crear, con los argumentos que he recogido, un momento (entrevista a un músico bajista experimentado, 4 de marzo de 2016, transcripción $n^{\circ} .17$, p. 3).

Siempre que uno improvisa está haciendo, de algún modo, algo que uno ya ha hecho antes, pero en otro contexto. Entonces la improvisación es un momento 
de adrenalina y de emoción, pero yo me preparo mucho para poder hacer una improvisación (entrevista a un músico guitarrista experimentado, 10 de marzo de 2016, transcripción $n^{\circ} .16$, p. 2).

Debe haber unos presupuestos muy básicos, por ejemplo de ritmo, tienen que todos tocar al mismo ritmo, porque si no sería complicado. Hay algo que se llama sincronización (...) para poderse sincronizar se necesitan algunos presupuestos mínimos (entrevista a un músico guitarrista experimentado, 6 de marzo de 2016, transcripción $n^{\circ} .18$, p. 5).

Así, a pesar de que de la manera más básica se considere que improvisar consiste en "hacer algo de pronto, sin estudio ni preparación" ${ }^{22}$, a partir de los resultados de esta investigación es posible identificar que este fenómeno no nace ex nihilo o, en otras palabras, que no aparece de la nada, inscrito de repente en una tabula rasa. La improvisación se alimenta del 'tiempo vivido' (Minkowski, 2005), tanto por los actores como por la propia organización. Esto en vinculación con una realidad en devenir (Tsoukas \& Chia, 2002), en plena realización al interior de un contexto específico (Turner, Mitchell, \& Bettis, 2013; Turner \& Rindova, 2012). En éste la autonomía existe en la dependencia (Von Foerster, 2003): se da la libertad de improvisar, pero al interior de una partitura más o menos determinada y la sincronización (Ajit, 2008; Grieco \& Lilja, 1996) o, el orden, emergen entonces de un aparente desorden (McMillan \& Carlisle, 2007; Sanabria, 2014a; Stacey, 1993).

Como resultado de lo anterior, otros asuntos centrales también se afectan. El liderazgo en la formación de las estrategias emergentes, por ejemplo, es más bien distribuido, en particular, en virtud de la improvisación. Esto demanda, como se requiere también en un conjunto musical, la existencia de confianza entre los miembros de la organización (Cingano \& Pinotti, 2016; Fuglsang \& Jagd, 2015; Reuter,

$22 \quad$ Ver http://dle.rae.es/?w=diccionario.
Wijkström, \& Uggla, 2013); en particular, en el hecho de que cada uno tiene efectivamente las capacidades y la preparación necesarias para enfrentar las situaciones por venir $y$, en consecuencia, en que puede llegar a hacer bien su trabajo, favoreciendo así el resultado del grupo. En el mundo de la música, tal y como pudo evidenciarse en nuestro trabajo, esto es visible:

El director [lidera] (...), tiene clara la forma como en este pedazo va el tema, pero en el momento de la improvisación el dueño es el instrumentista. Yo considero que uno, como director, no le puede quitar el momento de inspiración al músico y decirle: "ino, se pasó dos compases!", "ino!, termine porque ahí va el pianista”, ino! Uno lo deja hasta que él termine y regularmente las formas son libres. Obviamente, dependiendo del tema (entrevista a un músico bajista experimentado, 4 de marzo de 2016, transcripción $\mathrm{n}^{\circ} .17$, p. 2).

Lo que se hace es asignar papeles y momentos. Entonces, empezamos todos al tiempo, empiezas tú el tiempo que tú quieras, nos das una señal que se llama "on cue", que es con los ojos y con el sonido. Uno le dice a la siguiente persona lo que ya se tiene estipulado y después la siguiente y la siguiente, hasta que ya todos lo hacen y [luego] hay un cierre (entrevista a un músico guitarrista experimentado, 10 de marzo de 2016, transcripción $\mathrm{n}^{\circ} .16$, p. 1).

Ahora bien, en el mundo de la música es evidente que para que un músico de jazz, por ejemplo, pueda improvisar adecuadamente, es necesario que éste adquiera determinadas habilidades cognitivas, físicas, rítmicas y melódicas, entre otras. Sin embargo, en el caso de la improvisación estratégica, no es claro qué tipo de habilidades se requieren (ver la sección de conclusiones). Este es un asunto en el que es necesario profundizar aún más y cuyo abordaje no es simple. En efecto, puede que la experiencia o la formación académica lleguen eventualmente a ser una 
parte importante en estos procesos; sin embargo, en la práctica, es posible observar casos de directivos que, sin experiencia o sin formación, han logrado aportar positivamente al crecimiento, el desarrollo y la perdurabilidad de las organizaciones a su cargo.

Finalmente, en este estudio se ha evidenciado que es muy probable que la improvisación estratégica cumpla, en el contexto de las estrategias emergentes, un papel equiparable al que ocupa la planeación al interior de las estrategias deliberadas. Del mismo modo, el desarrollo de capacidades, en las primeras, puede llegar a cumplir un papel similar al del uso de modelos en las segundas.

\section{Conclusiones}

Esta investigación, desde su origen, buscó aportar al actual nivel de comprensión en relación con las estrategias emergentes en las organizaciones. Con este fin, se recurrió al uso de un concepto aparentemente opuesto al de 'planeación' y muy cercano a este tipo de iniciativas: la improvisación. Considerando que, entre otros lugares (como el teatro), este encuentra un espacio privilegiado en el mundo de la música, del que se ha nutrido para su desarrollo, se acudió en nuestro trabajo al saber propio de ese dominio, en particular, haciendo uso de 'la metáfora' como medio para tratar de entenderlo y alcanzar el objetivo propuesto para el presente estudio.

Como se puso en evidencia en la revisión de la literatura, en efecto, dentro de las múltiples representaciones que han surgido acerca de la noción de estrategia, dos de ellas se destacan: por un lado, se encuentra la mirada clásica, la cual la vincula con la idea de un plan deliberado; por el otro, una mirada crítica, que encuentra en Mintzberg a su más destacado exponente, la cual la acerca más bien a un fenómeno cuya definición se da en el día a día de la organización, en la acción que se realiza en el cotidiano. En el primer caso, se abre el espacio a la consideración de las estrategias deliberadas y, en el segundo, de las emergentes. Ahora bien, en la tradición del campo se ha privilegiado el estudio $y$ desarrollo de las primeras, haciendo uso, pero no profundizando en la misma medida que estas, en el trabajo acerca de las segundas.
Lo anterior alejó el interés de la mayoría de los investigadores en este campo por conceptos que, dada su naturaleza, están más vinculados con las estrategias emergentes que con las deliberadas, entre ellos, de algunos como el de 'improvisación'. Sin embargo, en otras áreas del saber, como la música - conectada ya por varios autores a los estudios organizacionales, a través del uso de la metáfora como recurso teórico-, ésta ha sido ampliamente acogida, desarrollada y aplicada.

Considerando estos aspectos y sus fundamentos, emergió una pregunta de investigación, la cual inspiró y dio sentido al estudio realizado, a saber: ¿qué lugar puede ocupar la improvisación en la formación de estrategias emergentes? Con base en los resultados del trabajo realizado se identifica que, en realidad, la improvisación ocupa un lugar central en el desarrollo de este tipo de estrategias. Ésta, de hecho, establece un tipo de puente que permite ponerlas en relación con las estrategias deliberadas y comprender, entre otras cosas, que unas y otras se complementan y coexisten en el entorno organizacional. Además, se encuentra que la improvisación es inevitable en este medio y que tiene una mayor intensidad en el 'cómo' de la estrategia (su implementación), que en el 'que' (su formulación). Finalmente, se observa que, a pesar de que su definición más básica y común no reconozca esto, la improvisación no nace de la nada, no es una creación ex nihilo. Ella implica una preparación, tanto en el mundo musical como en el organizacional. En efecto, para poder improvisar adecuadamente, hay que estar preparado.

Estos son entonces los principales elementos de respuesta encontrados a la pregunta de investigación y, en consecuencia, constituyen las principales contribuciones del trabajo realizado al campo de la estrategia organizacional, en particular, al nivel actual de comprensión en relación con las estrategias emergentes y el rol que estas ocupan al interior del mismo.

Nuestra investigación puede aportar igualmente, en particular, a tres tipos de actores del campo de los estudios organizacionales: 1) a los directivos: para que ellos comprendan de mejor manera el rol que 
ocupa la improvisación en la estrategia organizacional y, así, puedan ponderarlo adecuadamente y valorar la necesidad de prepararse bien para poder llevarla a cabo en las organizaciones a su cargo (en particular, considerando lo relativo al 'cómo' de la estrategia más que al 'qué'); 2) a los investigadores: en función de lo anterior, para que se insista en la necesidad de seguir desarrollando conceptos como, por ejemplo, el de situational awareness, así como para incentivar en ellos un trabajo aún más arduo acerca de las estrategias emergentes, la improvisación y el uso explicativo de las metáforas como un recurso valioso para aportar a la construcción de teoría, y 3) a los educadores: para que aquellos que principalmente centran sus esfuerzos hoy en la enseñanza de procesos y procedimientos, preestablecidos en las múltiples metodologías existentes para la definición de la estrategia organizacional, consideren también en sus cursos metas de aprendizaje vinculadas con capacidades dinámicas tan relevantes como la improvisación estratégica, así como los diferentes aspectos que esta implica para la formación de un directivo.

Estos resultados, por supuesto, tienen ciertos alcances y no están exentos de limitaciones. Así, por ejemplo, es claro que dado el diseño de investigación planteado y, en particular, el posicionamiento epistemológico que lo inspiró (el interpretativismo), el trabajo aquí presentado no pretende que sus conclusiones sean 'válidas' para todo tipo de organización en todo contexto espaciotemporal. La única generalización que eventualmente puede llegar a hacerse de lo aquí hallado es teórica, puesto que el trabajo, a partir del estudio longitudinal, detallado $y$ en profundidad realizado en el contexto de una organización, pretendió, desde sus inicios, aportar al nivel de comprensión que se tiene de un tipo de estrategias en las organizaciones: las estrategias emergentes, nada más y nada menos.

De este modo, así como un estudio acerca de las agresiones presentes entre los miembros de una determinada familia puede llegar a proveer elementos que permitan enriquecer y mejorar el nivel de comprensión del concepto de 'violencia intrafamiliar', por ejemplo, esto no quiere decir que las prácticas violentas encontradas en ese grupo familiar especí- fico sean generalizables, sucedan del mismo modo en otras familias y se apliquen a todas las existentes en un determinado tiempo y lugar. En realidad, no es usual encontrar algún tipo de comportamiento generalizable (al 100\%) en el contexto social.

Finalmente, gracias a la realización de este trabajo, se vislumbra una serie de investigaciones futuras que podrian llegar a desarrollar aportes complementarios alrededor de la problemática aquí abordada. Entre estas, en particular, se considera relevante resaltar las siguientes:

1. Se encuentra que para improvisar hay que estar preparados, pero ¿qué tipo de habilidades se requieren para poder improvisar de manera adecuada?

2. La improvisación está en todo lugar en la formación de estrategias, principalmente de las emergentes, pero ¿de qué manera es afectada por - y cómo se interrelaciona con- factores como la confianza, la delegación, la autonomía, la preparación, la libertad, el establecimiento de pautas, los objetivos prestablecidos, el contexto, el talento, la intersubjetividad, la sincronización de acciones individuales en un patrón colectivo, el reconocimiento mutuo, la trayectoria de las relaciones entre los actores, la temporalidad, el tipo de liderazgo, la incertidumbre, el riesgo, el aprendizaje y la dependencia de las condiciones iniciales y de la historia propia de los sistemas complejos?

3. La metáfora musical es un recurso valioso para comprender de manera más amplia el concepto de improvisación y, por esta vía, el de estrategias emergentes, pero ¿qué otras metáforas podrían aportar también al mismo propósito (p. ej., el mundo del teatro, del deporte, etc.)?

4. Conceptos relevantes fueron abordados en este trabajo aunque, por el objetivo que este perseguía, los mismos no fueron ampliamente desarrollados aquí. Se considera entonces valioso poder llegar a hacerlo en los próximos años. Se destacan en particular dos de ellos: a) el liderazgo distribuido, que remite a nociones como 
la de 'heterarquía' en la formación de las estrategias (Fairtlough, 2005; Sanabria, 2014a) y b) la existencia de múltiples 'voces' simultáneas expresando cada una su propia idea, pero formando, en conjunto, un 'todo armónico' en la construcción de la realidad organizacional. Esto último, desde la metáfora musical, puede relacionarse específicamente con el concepto de 'polifonía'.

Parece necesario entonces llevar a cabo nuevas investigaciones que permitan ampliar, en función de estos aspectos y de otros eventualmente identificados por los lectores, con ocasión de este trabajo, los conceptos abordados en el marco de esta investigación. Entre ellos, por supuesto, el de 'improvisación estratégica'.

\section{Referencias}

Abbott, A. D. (2004). Methods of discovery: Heuristics for the social sciences. Nueva York: W.W. Norton \& Co.

Ackoff, R. L. (1970). A concept of corporate planning. Nueva York: Wiley-Interscience.

Ajit, K. (2008). Synchronization: Moving beyond re-engineering. The Journal of Business Strategy, 29(3), 51-54.

Aktouf, O. (2001). La administración entre tradición y renovación (3a ed.). Cali: Artes Gráficas del Valle.

Alvesson, M. (1996). Leadership studies: From procedure and abstraction to reflexivity and situation. The Leadership Quarterly, 7(4), 455-485.

Alvesson, M. (2011). Interpreting interviews. Londres: SAGE.

Alvesson, M., \& Ashcraft, K. L. (2012). Interviews. En G. Symon \& C. Cassell (Eds.), Qualitative organizational research: Core methods and current challenges (pp. 239-257). Los Ángeles - Londres: SAGE.

Alvesson, M., \& Sköldberg, K. (2009). Reflexive methodology: New vistas for qualitative research (2nd ed.). Londres: SAGE.

Alvesson, M., \& Spicer, A. (2011). Metaphors we lead by: Understanding leadership in the real world. Londres: Routledge.

Andersen, T. J., \& Nielsen, B. B. (2009). Adaptive strategy making: The effects of emergent and intended strategy modes. European Management Review, 6(2), 94-106.

Andrews, K. R. (1971/1980). The concept of corporate strategy (Rev. ed.). Homewood: R. D. Irwin.

Ansoff, H. I. (1965). Corporate strategy. An analytic approach to business policy for growth and expansion. Nueva York: McGraw-Hill.

Ansoff, H. I. (1991). Critique of Henry Mintzberg's 'The design school: Reconsidering the basic premises of strategic management'. Strategic Management Journal, 12(6), 449-461.
Ansoff, H. I., \& Hayes, R. L. (1976). Introduction. En H. I. Ansoff, R. P. Declerck \& R. L. Hayes (Eds.), From strategic planning to strategic management (pp. 1-12). Londres - Nuva York: Wiley.

Ansoff, H. I., \& McDonnell, E. J. (1990). Implanting strategic management (2nd ed.). Nueva York: Prentice Hall.

Ansoff, H. I., Declerck, R. P., \& Hayes, R. L. (1976). From strategic planning to strategic management. En H. I. Ansoff, R. P. Declerck \& R. L. Hayes (Eds.), From strategic planning to strategic management (pp. 39-78). Londres - Nueva York: Wiley.

Arshad, D. (2011). Understanding organisational improvisation: Foundations and performance implications. Doctor of Philosophy, Loughborough University, Loughborough.

Barnett, S. (1996). Style and strategy: New metaphors, new insights. European Management Journal, 14(4), 347-355.

Barney, J. B. (1997). Gaining and sustaining competitive advantage. Reading: Addison-Wesley Pub. Co.

Barrett, F. J. (1998). Coda-Creativity and improvisation in jazz and organizations: Implications for organizational learning. Organization Science, 9(5), 605-622.

Bastien, D. T., \& Hostager, T. J. (1988). Jazz as a process of organizational innovation. Communication Research, 15(5), 582-602.

Bastien, D., \& Hostager, T. (1988). Jazz as a process of organizational innovation. Comunication research, 15, 582-602.

Beatty, J. E. (2004). Grades as money and the role of the market metaphor in management education. Academy of Management Learning \& Education, 3(2), 187-196.

Berendt, J. E. (1994). El jazz: de nueva orleans a los años ochenta. Bogotá: Fondo de Cultura Económica.

Berkowitz, A. (2010). The improvising mind: Cognition and creativity in the musical moment. Nueva York: Oxford University Press.

Bessudo, J.-C. (2007). Improvisación estratégica (2a ed.). Bogotá: Editorial Planeta.

Bowman, E. H., Singh, H., \& Thomas, H. (2002). The domain of strategic management: History and evolution. En A. M. Pettigrew, H. Thomas \& R. Whittington (Eds.), Handbook of strategy and management (pp. 31-51). Londres: SAGE.

Bozkurt, Ö. Ç., \& Kalkan, A. (2013). Strategic focus in turkish smes: Emergent or deliberate strategies? Procedia - Social and Behavioral Sciences, 99, 929-937.

Burrell, G. (1996). Normal science, paradigms, metaphors, discourses and genealogies of analysis. En S. Clegg, C. Hardy \& W. R. Nord (Eds.), Handbook of organization studies (pp. 642-658). Londres - Thousand Oaks: SAGE.

Burrell, G., \& Morgan, G. (1979). Sociological paradigms and organisational analysis: Elements of the sociology of corporate life. Londres: Heinemann Educational.

Chaffee, E. E. (1985). Three models of strategy. Academy of Management Review, 10(1), 89-98.

Chandler, A. D. (1962/1990). Strategy and structure: Chapters in the history of the industrial enterprise. Cambridge: M.I.T. Press. 
Chia, R. C. H., \& Holt, R. (2009). Strategy without design: The silent efficacy of indirect action. Cambridge, - Nueva York: Cambridge University Press.

Cingano, F., \& Pinotti, P. (2016). Trust, firm organization, and the pattern of comparative advantage. Journal of International Economics, 100, 1-13.

Collier, J. L. (1993). Jazz: The American theme song. Nueva York: Oxford University Press.

Cornelissen, J. P. (2005). Beyond compare: Metaphor in organization theory. The Academy of Management Review, 30(4), 751-764.

Cornelissen, J. P., Oswick, C., Christensen, L. T., \& Phillips, N. (2008). Metaphor in organizational research: Context, modalities and implications for research --- Introduction. Organization Studies, 29(1), 7-22.

Creswell, J. W. (2014). Research design: Qualitative, quantitative, and mixed methods approaches (4th ed.). Thousand Oaks: SAGE.

Cunha, M. P. E., \& Cunha, J. V. D. (2006). Towards the improvising organisation. Business Leadership Review, III(IV), 1-6.

Cunha, M. P. e., Clegg, S. R., \& Kamoche, K. (2012). Improvisation as "real time foresight". Futures, 44(3), 265-272.

Czarniawska, B. (2004). Metaphors as enemies of organizing, or the advantages of a flat discourse. International Journal of the Sociology of Language, 166(1), 45-65.

Czarniawska, B. (2011). What comes first, the egg or the chicken? Or: Where do the metaphors we use in our research come from? En A. Carlsen \& J. E. Dutton (Eds.), Research alive: Exploring generative moments in doing qualitative research (pp. 50-57). Malmö: Liber-Copenhagen Business School Press.

Davidson, C. (2009). Transcription: Imperatives for qualitative research. International Journal of Qualitative Methods, 8(2), 35-52.

De Contreras, A. (2005). La improvisación en el jazz: una introducción al lenguaje del jazz tanto desde sus convenciones externas como internas. - Primera parte. Musicalia, 3, 1-1.

De Geus, A. (1997). The living company: Growth learning and longevity in business. Boston: Harvard Business School Press.

Denzin, N. K., \& Lincoln, Y. S. (Eds.). (2011). The SAGE handbook of qualitative research (4th ed.). Thousand Oaks: SAGE.

Dess, G. G., \& Lumpkin, G. T. (2005). Emerging issues in strategy process research. En M. A. Hitt, R. E. Freeman \& J. S. Harrison (Eds.), The Blackwell handbook of strategic management (pp. 3-34). Oxford - Malden,: Blackwell.

Duxbury, T. (2014). Improvising entrepreneurship. Technology Innovation Management Review, 4(7), 22-26.

Easterby-Smith, M., Thorpe, R., \& Jackson, P. (2012). Management research (4th ed.). Thousand Oaks: SAGE.

Eisenhardt, K. M., \& Martin, J. A. (2000). Dynamic capabilities: What are they? Strategic Management Journal, 21(10-11), 1105-1121.

Etkin, J., \& Schvarstein, L. (2000). Identidad de las organizaciones: Invariancia y cambio. Buenos Aires: Paidós.
Fairtlough, G. (2005). The three ways of getting things done: Hierarchy, heterarchy \& responsible autonomy in organizations. Bridport: Triarchy Press.

Falconi, V. (1996). Gerenciamento pelas diretrizes (Hoshin Kanri) (2a ed.). Belo Horizonte: Fundação Christiano Ottoni, Escola de Engenharia da UFMG.

Fayol, H. (1916/1917). Administration industrielle et générale: Prévoyance-organisation-commandement-coordination - controle (extrait du bulletin de la société de l'industrie minérale. $3^{e}$ livraison, de 1916). París: H. Dunod et E. Pinat, Éditeurs.

Flick, U. (2007). Designing qualitative research. Londres - Thousand Oaks - Nueva Delhi - Singapur: SAGE.

Forgues, B., \& Vandangeon-Derumez, I. (2007). Analyses longitudinales. En R.-A. Thiétart (Ed.), Méthodes de recherche en management (3e ed., pp. 439-465). París: Dunod.

Fuglsang, L., \& Jagd, S. (2015). Making sense of institutional trust in organizations: Bridging institutional context and trust. Organization, 22(1), 23-39.

Genelot, D. (2001). Manager dans la complexité : réflexions à l'usage des dirigeants (3e ed.). París: INSEP consulting éd.

Girin, J. (1989). L'opportunisme méthodique dans les recherches sur la gestion des organisations. Ponencia presentada en el Congrès de l'Association Française pour la Cybernétique Economique et Technique (AFCET) - Journée d'étude la recherche-action en action et en question, École Centrale de Paris.

Glenn, A. B. (2009). Document analysis as a qualitative research method. Qualitative Research Journal, 9(2), 27-40.

Goatly, A. (1997). The language of metaphors. Londres: Routledge.

Golsorkhi, D., Rouleau, L., Seidl, D., \& Vaara, E. (2010a). Introduction: What is strategy as practice? En D. Golsorkhi, L. Rouleau, D. Seidl \& E. Vaara (Eds.), Cambridge handbook of strategy as practice (pp. 1-20). Cambridge - Nueva York: Cambridge University Press.

Golsorkhi, D., Rouleau, L., Seidl, D., \& Vaara, E. (Eds.). (2010b). Cambridge handbook of strategy as practice. Cambridge Nueva York: Cambridge University Press.

Goold, M. (1992). Research notes and communications design, learning and planning: A further observation on the design school debate. Strategic Management Journal, 13(2), 169-170.

Gordon, C. (2013). Beyond the observer's paradox: The audiorecorder as a resource for the display of identity. Qualitative Research, 13(3), 299-317.

Grant, D., \& Oswick, C. (1996). Organizational discourse: Metaphors in organizational theory and behaviour. United Kingdom: KMPC.

Grieco, M., \& Lilja, K. (1996). Research note: 'Contradictory couplings': Culture and the synchronization of opponents. Organization Studies, 17(1), 131-137.

Guba, E. G., \& Lincoln, Y. S. (1994). Competing paradigms in qualitative research. En N. K. Denzin \& Y. S. Lincoln (Eds.), Handbook of qualitative research (pp. 105-117). Thousand Oaks - Londres - Nueva Delhi: SAGE. 
Hafsi, T. (2000). Le champ de la recherche en stratégie : A la recherche d'un bâton d'aveugle. En M. Côté \& T. Hafsi (Eds.), Le management aujourd'hui. Une perspective nord-américaine (pp. 1460-1469). Laval - París: Presses de l'Université Laval - Economica.

Hafsi, T., \& Thomas, H. (2005). The field of strategy: In search of a walking stick. European Management Journal, 23(5), 507-519.

Hamel, G., \& Prahalad, C. K. (1989). Strategic intent. Harvard Business Review, 67(3), 63-76.

Hatch, M. J. (1999). Exploring the empty spaces of organizing: How improvisational jazz helps redescribe organizational structure. Organization Studies, 20(1), 75-100.

Hatch, M. J., \& Weick, K. E. (1998). Critical resistance to the jazz metaphor. Organization Science, 9(5), 600-604.

Helfat, C. E., Finkelstein, S., Mitchell, W., Peteraf, M. A., Singh, H., Teece, D. J., \& Winter, S. G. (2007). Dynamic capabilities: Understanding strategic change in organizations. Malden: Blackwell Pub.

Helms-Mills, J., Dye, K., \& Mills, A. J. (2009). Understanding organizational change. Abingdon - Nueva York: Routledge.

Hennink, M., \& Weber, M. B. (2013). Quality issues of court reporters and transcriptionists for qualitative research. Qualitative Health Research, 23(5), 700-710.

Heracleous, L., \& Jacobs, C. D. (2011). Crafting strategy: Embodied metaphors in practice. Cambridge - Nueva York: Cambridge University Press.

Hernández, J. E., Montoya, I. A., \& Montoya, L. A. (2015). The mourning of the deliberate strategy for the arising of the emergent strategy. TOJET: The Turkish Online Journal of Educational Technology, Special Issue 1 for IETC 2015, 547-556.

Hill, R. C., \& Levenhagen, M. (1995). Metaphors and mental models: Sensemaking and sensegiving in innovative and entrepreneurial activities. Journal of Management, 21(6), 1057-1074.

Hitt, M. A., Ireland, R. D., \& Hoskisson, R. E. (2013). Strategic management: Competitiveness \& globalization (10e ed.). Australia - Mason: South-Western / Cengage Learning.

Hofer, C. W., \& Schendel, D. (1978). Strategy formulation: Analytical concepts. St. Paul: West Pub. Co.

Humphreys, M., Ucbasaran, D., \& Lockett, A. (2012). Sensemaking and sensegiving stories of jazz leadership. Human Relations, 65(1), 41-62.

Hutzschenreuter, T., \& Kleindienst, I. (2006). Strategy-process research: What have we learned and what is still to be explored. Journal of Management, 32(5), 673-720.

Inns, D. (2002). Metaphor in the literature of organizational analysis: A preliminary taxonomy and a glimpse at a humanities-based perspective. Organization, 9(2), 305-330.

Jarzabkowski, P. (2005). Strategy as practice: An activity-based approach. Londres - Thousand Oaks: SAGE.

Johnson, G., Melin, L., \& Whittington, R. (2003). Guest editors' introduction: Micro strategy and strategizing: Towards an activitybased view. Journal of Management Studies, 40(1), 3-22.
Kamoche, K. N., Cunha, M. P. e., \& Cunha, J. V. d. (Eds.). (2002). Organizational improvisation. Londres: Routledge.

Kamoche, K., Cunha, M. P. e., \& Cunha, J. V. d. (2003). Towards a theory of organizational improvisation: Looking beyond the jazz metaphor. Journal of Management Studies, 40(8), 2023-2051.

Kamoche, K., \& Pina e Cunha, M. (2001). Minimal structures: From jazz improvisation to product innovation. Organization Studies, 22/5, 733-764.

Katz, J. (2015). Situational evidence: Strategies for causal reasoning from observational field notes. Sociological Methods \& Research, 44(1), 108-144.

Kipping, M., \& Cailluet, L. (2010). Mintzberg's emergent and deliberate strategies: Tracking Alcan's activities in europe, 1928-2007. Business History Review, 84(1), 79-104.

Kvale, S. (2007). Doing interviews. Thousand Oaks: SAGE.

Learned, E. P., Christensen, C. R., Andrews, K. R., \& Guth, W. D. (1965/1969). Business policy: Text and cases (Revised ed.). Homewood: R. D. Irwin.

Leatherdale, W. H. (1974). The role of analogy, model, and metaphor in science. Amsterdam - Nueva York: North-Holland Pub. Co. - American Elsevier Pub. Co.

Letiche, H., \& van Uden, J. (1998). Answers to a discussion note: On the 'metaphor of the metaphor'. Organization Studies, 19(6), 1029-1033.

Liedtka, J. M. (1998). Strategic thinking: Can it be taught? Long Range Planning, 31(1), 120-129.

Lofland, J., Lofland, L. H., Snow, D. A., \& Anderson, L. (2006). Analyzing social settings: A guide to qualitative observation and analysis (4th ed.). Belmont: Wadsworth/Thomson Learning.

Lortat-Jacob, B. (Ed.). (1987). L'improvisation dans les musiques de tradition orale. París: Selaf.

Lowe, A., \& Jones, A. (2004). Emergent strategy and the measurement of performance: The formulation of performance indicators at the microlevel. Organization Studies, 25(8), 1313-1337.

Manning, P. K. (1979). Metaphors of the field: Varieties of organizational discourse. Administrative Science Quarterly, 24(4), 660-671.

Mantere, S., Sillince, J. A. A., \& Hämäläinen, V. (2007). Music as a metaphor for organizational change. Journal of Organizational Change Management, 20(3), 447-459.

McDaniel Jr., R. R. (2007). Management strategies for complex adaptive systems: Sensemaking, learning, and improvisation. Performance Improvement Quarterly, 20(2), 21-42.

McMillan, E., \& Carlisle, Y. (2007). Strategy as order emerging from chaos: A public sector experience. Long Range Planning, 40(6), 574-593.

Meyer, A., Frost, P. J., \& Weick, K. E. (1998). The organization science jazz festival: Improvisation as a metaphor for organizing. Organization Science, 9(5), 540-542.

Mihram, D., \& Mihram, G. A. (1974). Human knowledge: The role of models, metaphors, and analogy. International Journal of General Systems, 1(1), 41-60. 
Miller, D., \& Friesen, P. H. (1982). The longitudinal analysis of organizations: A methodological perspective. Management Science, 28(9), 1013-1034.

Minkowski, E. (2005). Le temps vécu : études phénoménologiques et psychopathologiques (2e éd.). París: Quadrige/PUF.

Mintzberg, H. (1971). Managerial work: Analysis from observation. Management Science, 18(2), B-97-B-110.

Mintzberg, H. (1973). Strategy-making in three modes. California Management Review, 16(2), 44-53.

Mintzberg, H. (1975). The manager's job: Folklore and fact. Harvard Business Review, 53(4), 49-61.

Mintzberg, H. (1976). Planning on the left side and managing on the right. Harvard Business Review, 54(4), 49-58.

Mintzberg, H. (1977). Strategy formulation as a historical process. International Studies of Management \& Organization, 7(2), 28-40.

Mintzberg, H. (1978). Patterns in strategy formation. Management Science, 24(9), 934-948.

Mintzberg, H. (1981). What is planning anyway? Strategic Management Journal, 2(3), 319-324.

Mintzberg, H. (1987a). Crafting strategy. Harvard Business Review, 65(4), 66-75.

Mintzberg, H. (1987b). The strategy concept I: Five Ps for strategy. California Management Review, 30(1), 11-24.

Mintzberg, H. (1990a). The design school: Reconsidering the basic premises of strategic management. Strategic Management Journal, 11(3): 171-195.

Mintzberg, H. (1990b). Does decision get in the way? (in Hickson's "studying deciding: An exchange of views between mintzberg and waters, pettigrew, and butier"). Organization Studies, 11(1), 1-6.

Mintzberg, H. (1990c). Strategy formation: Schools of thought. En J. W. Frederickson (Ed.), Perspectives on strategic management (pp. 105-235). Nueva York: Harper Business.

Mintzberg, H. (1991). Learning 1, planning 0: Reply to Igor Ansoff. Strategic Management Journal, 12(6), 463-466.

Mintzberg, H. (1994). The rise and fall of strategic planning: Reconceiving roles for planning, plans, planners. Nueva York: Free Press.

Mintzberg, H. (Ed.). (2007). Tracking strategies: Toward a general theory. Oxford - Nueva York: Oxford University Press.

Mintzberg, H., \& Waters, J. A. (1985). Of strategies, deliberate and emergent. Strategic Management Journal, 6(3), 257-272.

Mintzberg, H., Ahlstrand, B. W., \& Lampel, J. (1998). Strategy safari: A guided tour through the wilds of strategic management. Nueva York: Free Press.

Mintzberg, H., Raisinghani, D., \& Théorêt, A. (1976). The structure of 'unstructured' decision processes. Administrative Science Quarterly, 21(2), 246-275.

Mogalakwe, M. (2006). The use of documentary research methods in social research. African Sociological Review, 10(1), 221-230.

Montgomery, C. A., \& Porter, M. E. (1991). Strategy: Seeking and securing competitive advantage. Boston: Harvard Business School Press.
Montoya, I. A. (2010). Una contribución a la comprensión de las estrategias deliberadas y emergentes de las organizaciones, desde una perspectiva evolutiva. Tesis de Doctorado en Ciencias Económicas, Universidad Nacional de Colombia, Bogotá. Recuperado de http://www.bdigital. unal.edu.co/2141/1/UNA_CONTRIBUCI\%C3\%93N_A LA_COMPRENSI\%C3\%93N_DE_LAS_ESTRATEGIAS_DELIBER.pdf

Montoya, I. A., \& Montoya, L. A. (2010, 3 al 6 de noviembre). Principales aportes en estrategia emergente. Ponencia presentada en la XLV Asamblea Anual del Consejo Latinoamericano de Escuelas de Administración (Cladea), Cartagena de Indias, Colombia.

Montoya, I. A., \& Montoya, L. A. (2013). La formación de estrategias deliberadas y emergentes: una propuesta a partir de definiciones básicas de una metodología de sistemas suaves. Revista Facultad de Ciencias Económicas: Investigación y reflexión, XXI(2), 67-95.

Montoya, I. A., \& Montoya, L. A. (2015). Comprensión del concepto de emergencia, desde el aporte de Holland, Kauffman y Andrade. Innovar, 25(57), 27-43.

Montoya, I. A., Montoya, L. A., \& Castellanos, O. F. (2010). La metáfora organizacional: alternativa de entendimiento procedente de otras ciencias. Revista Facultad de Ciencias Económicas: Investigación y reflexión, XVIII(1), 75-86.

Montoya, L. A., Castellanos, O. F., \& Montoya, I. A. (2004). La gerencia genética: una metáfora biológica aplicada a la gestión de la biotecnología. Innovar(24), 93-104.

Montuori, A. (2012). The complexity of improvisation and the improvisation of complexity: Social science, art and creativity. En S. O. Johannessen \& L. Kuhn (Eds.), Complexity in organization studies (Vol. III: Implications and applications of complexity thinking in organization studies: Strategy, organizational dymamics and innovation, pp. 239-255). Los Ángeles: SAGE.

Morgan, G. (1980). Paradigms, metaphors, and puzzle solving in organization theory. Administrative Science Quarterly, 25(4), 605-622.

Morgan, G. (2006). Images of organization (Updated ed.). Thousand Oaks: SAGE.

Morin, E. (1981). La méthode I: La nature de la nature. París: Éditions du Seuil.

Nachmanovitch, S. (2004). Free play: la improvisación en la vida $y$ en el arte (2a ed.). Buenos Aires: Paidós.

Oakes, S. (2009). Freedom and constraint in the empowerment as jazz metaphor. Marketing Theory, 9(4), 463-485.

Örtenblad, A., Putnam, L., \& Trehan, K. (2013). 30 ${ }^{\text {th }}$ anniversary - beyond morgan's eight metaphors. Human Relations, 66(6), 879-881.

Pascale, R. T. (1999). Surfing the edge of chaos. Sloan Management Review, 40(3), 83-94.

Pascale, R. T., Millemann, M., \& Gioja, L. (2000). Surfing the edge of chaos: The laws of nature and the new laws of business. Nueva York: Three Rivers Press.

Patrick, M. (2008). Strategic improvisation. Journal of Business Strategy, 29(6), 59-61. 
Pettigrew, A. M. (1989). Longitudinal field research on change: Theory and practice. En R. Mansfield (Ed.), Frontiers of management (pp. 21-49). Londres - Nueva York: Routledge.

Pina e Cunha, M., \& Vieira da Cunha, J. (2012). Towards a complexity theory of strategy. En S. O. Johannessen \& L. Kuhn (Eds.), Complexity in organization studies (Vol. III: Implications and applications of complexity thinking in organization studies: Strategy, organizational dymamics and innovation, pp. 107-119). Los Ángeles: SAGE.

Ployhart, R. E., \& Vandenberg, R. J. (2010). Longitudinal research: The theory, design, and analysis of change. Journal of Management, 36(1), 94-120.

Porter, M. E. (1985). Competitive advantage: Creating and sustaining superior performance. Nueva York - Londres: Free Press - Collier Macmillan.

Porter, M. E. (1987). From competitive advantage to corporate strategy. Harvard Business Review, 65(3), 43-59.

Porter, M. E. (1996). What is strategy? Harvard Business Review, 74(6), 61-78.

Quinn, J. B. (1978). Strategic change: "Logical incrementalism". Sloan Management Review, 20(1), 7-21.

Quinn, J. B. (1980). Strategies for change: Logical incrementalism. Homewood: R.D. Irwin.

Quivy, R., \& Van Campenhoudt, L. (2006). Manuel de recherche en sciences sociales (3e ed.). Paris: Dunod.

Rasche, A. (2008). The paradoxical foundation of strategic management. Nueva York: Physica-Verlag.

Read, M. J. B. (2014). What coaches can learn from the history of jazz-based improvisation: A conceptual analysis. International Journal of Evidence Based Coaching and Mentoring, 12(2), 10-23.

Reuter, M., Wijkström, F., \& Uggla, B. K. (Eds.). (2013). Trust and organizations: Confidence across borders. Nueva York: Palgrave Macmillan.

Riviezzo, A., Skippari, M., \& Garofano, A. (2015). Who wants to live forever: Exploring 30 years of research on business longevity. Business History, 57(7), 970-987.

Roge, J. N. (1996). An analysis of deliberate and emergent strategies relative to porter's generic differentiator and cost leader: A bias and variance modeling approach. Developments In Business Simulation \& Experiential Exercises, 23, 68-73.

Rothman, A. M. (2014). ¿Cómo escribir canciones y componer música? www.escribircanciones.com.ar (Ed.) Recuperado de http://www.escribircanciones.com.ar/tienda/librodeescribircanciones.html

Saldaña, J. (Ed.). (2003). Longitudinal qualitative research: Analyzing change through time. Walnut Creek - Oxford: AltaMira Press.

Sanabria, M. (2004). El pensamiento organizacional estratégico: una perspectiva diacrónica. Innovar(24), 59-81.

Sanabria, M. (2014a). Réévaluation de l'approche cognitive du changement stratégique. Une étude des mutations des facultés de management colombiennes (2007-2012). Tesis de doctorado en Sciences de Gestion, Doctorat en Sciences de Gestion, Universidad de Caen Basse-Normandie, Caen, Francia.
Sanabria, M. (2014b). Universidad \& empresa (U\&E) y una lectura del discurso de la Escuela de Administración de la Universidad del Rosario respecto a la administración (A) y sus dos dimensiones: Dirección (D) y gerencia $(G)(A=D+G)$. Universidad \& Empresa, 16(27), 9-44.

Sanabria, M., \& Smida, A. (2015). El campo de la estrategia: origen y evolución. En H. García Cardona (Ed.), Administración en salud (pp. 119-215). Medellín: Biblioteca Jurídica Diké - Universidad CES.

Sanabria, M., Saavedra Mayorga, J. J., \& Smida, A. (2014). Los estudios organizacionales ('organization studies'): fundamentos, evolución y estado actual del campo. Bogotá: Escuela de Administración, Editorial Universidad del Rosario.

Schendel, D., \& Hofer, C. W. (Eds.). (1979). Strategic management: A new view of business policy and planning. Boston: Little, Brown.

Schober, M. F., \& Spiro, N. (2014). Jazz improvisers' shared understanding: A case study. Frontiers in Psychology, 5(Article 808), 1-21.

Schoenberg, A. (1950). Style and idea. Nueva York: Philosophical Library.

Schvarstein, L. (2000). Diseño de organizaciones: tensiones y paradojas. Buenos Aires: Paidós.

Simon, H. A. (1979). Rational decision making in business organization. American Economic Review, 69(4), 493-513.

Simon, H. A. (1982). Models of bounded rationality. Volume 2: Behavioral economics and business organization (Vol. 2). Cambridge - Londres: MIT Press.

Sommer, E., \& Weiss, D. (1995). Metaphors dictionary. Nueva York: Gale Research.

Soto, E., Soto, E., Dolan, S. L., Johansen Bertoglio, O., Losada i Marrodán, C., \& Cruz, C. E. (2005). Decisiones en ambientes de incertidumbre. Barcelona: Ediciones Deusto.

Soubeyran, O. (2014). Pensée aménagiste et improvisation : l'improvisation en jazz et l'écologisation de la pensée aménagiste. París: EAC Éditions des Archives contemporaines.

Stacey, R. (1993). Strategy as order emerging from chaos. Long Range Planning, 26(1), 10-17.

Stacey, R. D. (2001). Complex responsive processes in organizations: Learning and knowledge creation. Londres - Nueva York: Routledge.

Stacey, R. D. (2011). Strategic management and organisational dynamics: The challenge of complexity to ways of thinking about organisations (6th ed.). Harlow - Nueva York: Financial Times - Prentice Hall.

Stacey, R. D. (2012). Organizations as complex responsive processes of relating. En S. O. Johannessen \& L. Kuhn (Eds.), Complexity in organization studies (Vol. II: Theorizing complexity in organization studies, pp. 315-326). Los Ángeles: SAGE.

Styhre, A. (2002). How process philosophy can contribute to strategic management. Systems Research \& Behavioral Science, 19(6), 577-587.

Taber, T. D. (2007). Using metaphors to teach organization theory. Journal of Management Education, 31(4), 541-554. 
Taylor, B., \& Sinha, G. (2006). Research methodology. New Delhi: PHI Learning Private Limited.

Teece, D. J., Pisano, G., \& Shuen, A. (1997). Dynamic capabilities and strategic management. Strategic Management Journal, 18(7), 509-533.

Teoh, S., \& Wickramasinghe, N. (2012). Healthcare information systems design: Using a strategic improvisation model. En N. Wickramasinghe, R. Bali, R. Suomi \& S. Kirn (Eds.), Critical issues for the development of sustainable e-health solutions (pp. 33-48). Nueva York: Springer.

Thomas, C. (2015). Jazz improvisational approach to classical music. Horn Call: Journal of the International Horn Society, 45(3), 27-29.

Tsoukas, H., \& Chia, R. (2002). On organizational becoming: Rethinking organizational change. Organization Science, 13(5), 567-582.

Turner, S. F., \& Rindova, V. (2012). A balancing act: How organizations pursue consistency in routine functioning in the face of ongoing change. Organization Science, 23(1), 24-46.

Turner, S. F., Mitchell, W., \& Bettis, R. A. (2013). Strategic momentum: How experience shapes temporal consistency of ongoing innovation. Journal of Management, 39(7), 1855-1890.

Vainio, A. (2013). Beyond research ethics: Anonymity as "ontology', 'analysis' and 'independence'. Qualitative Research, 13(6), 685-698.

Van Maanen, J. (2011). Tales of the field: On writing ethnography (2nd ed.). Chicago: University of Chicago Press.

Vélez, Á. R., \& Garzón, M. A. (2005). La administración es algo más que gerencia. Revista Universidad \& Empresa, 7(8), 7-30.

Vendelø, M. T. (2009). Improvisation and learning in organizations - An opportunity for future empirical research. Management Learning, 40(4), 449-456.
Vera, D., \& Crossan, M. (2004). Theatrical improvisation: Lessons for organizations. Organization Studies, 25(5), 727-749.

Von Foerster, H. (2003). On self-organizing systems and their environments. En H. Von Foerster (Ed.), Understanding understanding: Essays on cybernetics and cognition (pp. 1-19). Nueva York: Springer.

Wang, C. L., \& Ahmed, P. K. (2007). Dynamic capabilities: A review and research agenda. International Journal of $M a-$ nagement Reviews, 9(1), 31-51.

Weick, K. E. (1995). Sensemaking in organizations. Thousand Oaks - Londres: SAGE.

Weick, K. E. (1998). Improvisation as a mindset for organizational analysis. Organization Science, 9(5), 543-555.

Weick, K. E. (2001). Making sense of the organization. Oxford: Blackwell Business.

Weick, K. E. (2009). Making sense of the organization. Vol. 2. The impermanent organization. Chichester: Wiley.

Wheelen, T. L., Hunger, J. D., Hoffman, A. N., \& Bamford, C. E. (2014). Strategic management and business policy: Globalization, innovation, and sustainability (14th ed.). Boston: Pearson.

Whittington, R. (1993). What is strategy, and does it matter? Londres - Nueva York: Routledge.

Whittington, R. (1996). Strategy as practice. Long Range Planning, 29(5), 731-735.

Wormeli, R. (2009). Metaphors \& analogies: Power tools for teaching any subject. Portland: Stenhouse Publishers.

Yanow, D., \& Schwartz-Shea, P. (Eds.). (2006). Interpretation and method: Empirical research methods and the interpretive turn. Armonk - Londres: M.E. Sharpe.

Ybema, S., Yanow, D., Wels, H., \& Kamsteeg, F. (Eds.). (2009). Organizational ethnography: Studying the complexities of everyday life. Los Ángeles - Londres: SAGE. 